\title{
Psychosocial factors partially mediate the relationship between mechanical hyperalgesia and self-reported pain
}

DOI:

10.1515/sjpain-2017-0109

Document Version

Accepted author manuscript

Link to publication record in Manchester Research Explorer

\section{Citation for published version (APA):}

Mason, K., O'Neill, T., Lunt, M., Jones, A., \& Mcbeth, J. (2018). Psychosocial factors partially mediate the relationship between mechanical hyperalgesia and self-reported pain. Scandinavian Journal of Pain, 18(1), 59-69. https://doi.org/10.1515/sjpain-2017-0109

\section{Published in:}

Scandinavian Journal of Pain

\section{Citing this paper}

Please note that where the full-text provided on Manchester Research Explorer is the Author Accepted Manuscript or Proof version this may differ from the final Published version. If citing, it is advised that you check and use the publisher's definitive version.

\section{General rights}

Copyright and moral rights for the publications made accessible in the Research Explorer are retained by the authors and/or other copyright owners and it is a condition of accessing publications that users recognise and abide by the legal requirements associated with these rights.

\section{Takedown policy}

If you believe that this document breaches copyright please refer to the University of Manchester's Takedown Procedures [http://man.ac.uk/04Y6Bo] or contact uml.scholarlycommunications@manchester.ac.uk providing relevant details, so we can investigate your claim.

\section{OPEN ACCESS}




\section{Scandinavian Journal of Pain \\ Psychosocial factors partially mediate the relationship between mechanical hyperalgesia and self-reported pain --Manuscript Draft--}

\begin{tabular}{|c|c|}
\hline Manuscript Number: & SJPAIN-D-17-00109R2 \\
\hline Article Type: & Observational studies \\
\hline Keywords: & $\begin{array}{l}\text { knee pain; quantitative sensory testing; sensitisation; psychosocial factors; altered } \\
\text { central processing }\end{array}$ \\
\hline Corresponding Author: & $\begin{array}{l}\text { Kayleigh J Mason, PhD } \\
\text { The University of Manchester } \\
\text { Manchester, LANCS UNITED KINGDOM }\end{array}$ \\
\hline First Author: & Kayleigh J Mason, PhD \\
\hline \multirow[t]{5}{*}{ Order of Authors: } & Kayleigh J Mason, PhD \\
\hline & Terence W O'Neill \\
\hline & Mark Lunt \\
\hline & Anthony $\mathrm{K}$ Jones \\
\hline & John McBeth \\
\hline Abstract: & 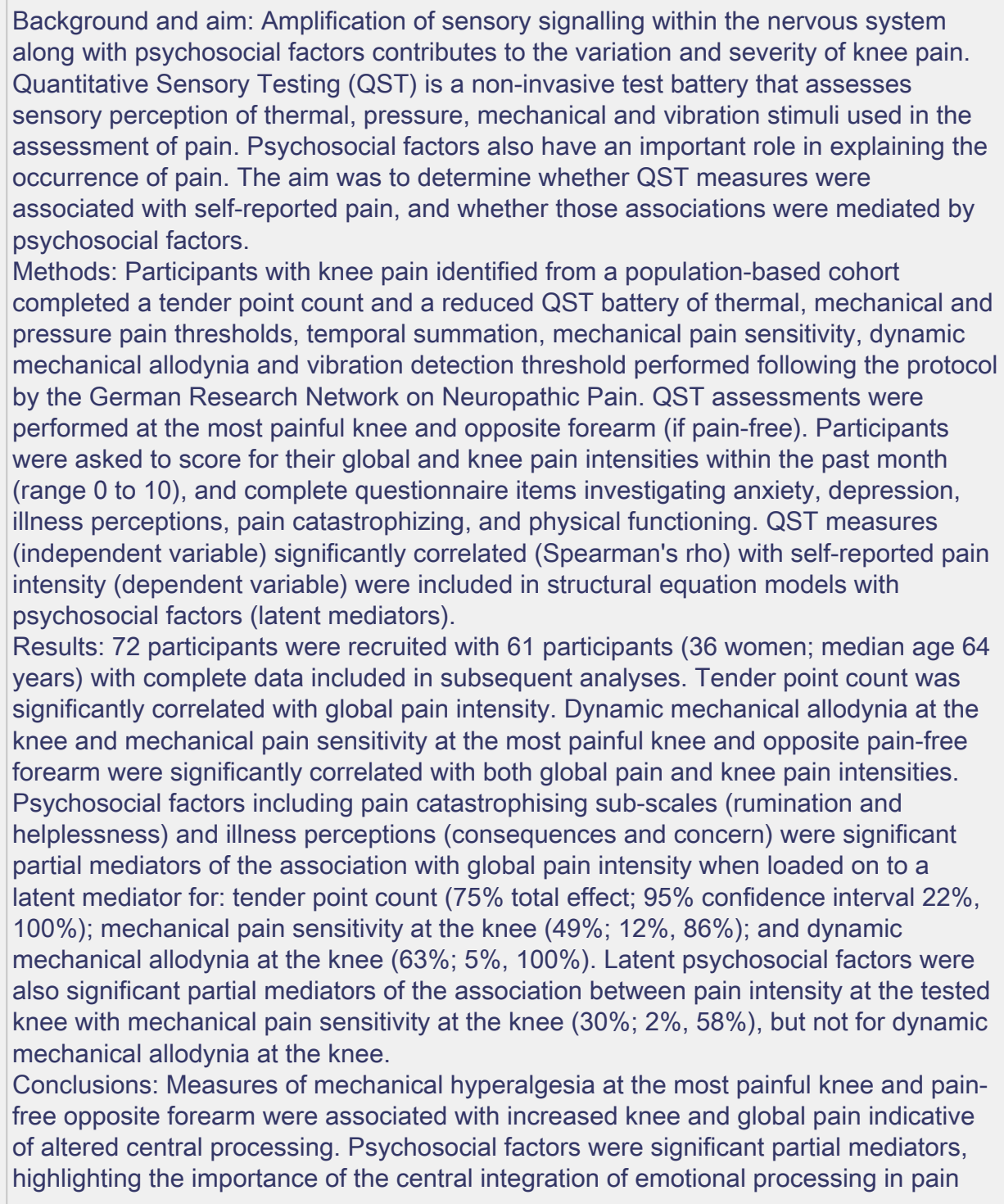 \\
\hline
\end{tabular}


perception.

Implications: Associations between mechanical hyperalgesia at the forearm and knee, psychosocial factors, and increased levels of clinical global and knee pain intensity provide evidence of altered central processing as a key mechanism in knee pain, with psychological factors playing a key role in the expression of clinical pain. 


\section{Ms. Ref. No.: SJPAIN-D-17-00109}

Title: Psychosocial factors partially mediate the relationship between mechanical hyperalgesia and self-reported pain Scandinavian Journal of Pain

Dear Dr. Kayleigh J Mason,

I have received the reviewers' comments (included below) on the manuscript "Psychosocial factors partially mediate the relationship between mechanical hyperalgesia and self-reported pain" and as you will see some modifications have been requested. One expert reviewer has a few further comments. I hope you can respond to these comments as soon as possible.

Due to our ongoing transition to a new Publisher, the editorial handling has taken a bit more time than normal. I hope you can accept this inconvenience.

I invite you to submit a new version taking into account all the issues raised. Please include an outline of each change made, with a point-by-point response to the referees and the reason for any rebuttal.

The deadline for re-submission is Dec 02, 2017.

We look forward to receiving your revised manuscript.

Yours sincerely,

Harald Breivik, MD, DMedSci

Editor in Chief

Scandinavian Journal of Pain 


\section{Reviewers' comments: SJPAIN-D-17-00109}

Reviewer \#1: The authors have to a large degree adequately revised the manuscript. However, there are still open critical issues.

Re comment 1: The authors should clarify that classical radiological assessments ( $x$-ray) is either not associated or very limited associated with pain in OA. Contrasting to this, MRI findings such as BMLs, synovitis or subchondral bone edemas seem to be associated with pain reports from patients (e.g. Barr et al.).

Response: We thank the reviewer for identifying this and have amended the third sentence of paragraph 1 to:

"Only moderate correlations exist between knee pain and the structural pathology of osteoarthritis $(\mathrm{OA})$ such as bone marrow lesions, synovitis and subchondral bone oedema, suggesting that altered central processing may be responsible for certain components of chronic pain [3,4]."

Re comment 3: The authors could be more specific and use terms such as "hyperalgesia", "allodynia" or "facilitated temporal summation" instead of "central sensitization".

Response: We have amended sentence 4, paragraph 1 of the Introduction to include the following. "In those with chronic pain, central sensitisation due to-altered central processing through amplifications of somatosensory inputs either via hyperalgesia (hypersensitivity to painful stimuli near a painful site) or allodynia (hypersensitivity to non-painful stimuli near a painful site), and the integration of emotional processing can contribute to the experience of pain in the absence of peripheral damage [5,6];"

Re comment 12: A reliability analysis regarding QST on 8-9 subjects is not very useful. A specific study on reliability should be conducted otherwise it is better removing this analysis from the manuscript.

Response: We have removed the section "2.7. Intra-rater reliability" from the methods.

Re comment 14: conducting 90 correlations without adjusting for multiple correlations is not advised and adjustment are needed. Alternatively, the authors should aim for a limited correlation analysis only including few parameters.

Response: We have included an asterisk next to each significant correlation in Table 3 and Table 4 where adjustment for the Bonferroni correction was satisfied. However, we have specified in section 2.8. "significant correlations $(\boldsymbol{p}<0.05)$ " were used to identify variables for our mediation analyses. Table 3 caption: * $\mathbf{p}<0.0029$ (0.05/17; Bonferroni Correction). Table 4 caption: * $\mathbf{p}<0.0036$ (0.05/14; Bonferroni Correction).

Re comment 18: It should be clarified in the manuscript that subjects who did not reach the CPT were classified as $\mathrm{OC}$, since this can have major implications for comparisons between studies. Response: We have added the following sentence to the end of section 2.6, paragraph 1. 
"Participants who did not achieve a painful sensation during cold or heat pain thresholds were categorised as $0^{\circ} \mathrm{C}$ and $50^{\circ} \mathrm{C}$, respectively."

Reviewer \#2: It appears to me that the Authors have responded well to the comments and questions of the reviewers. I have no further comments. 


\section{Highlights}

In people with higher levels of self-reported knee pain, we identified:

- Widespread mechanical hyperalgesia was correlated with greater pain intensity

- Catastrophising and illness perceptions were correlated with greater pain intensity

- Psychosocial factors mediate the relationship between pain and hyperalgesia

- Altered central processing is likely to be a key mechanism in knee pain 
Title: $\quad$ Psychosocial factors partially mediate the relationship between mechanical hyperalgesia and self-reported pain

Authors: $\quad$ Kayleigh J Mason ${ }^{1}$, Terence W O'Neill1, 2, 3, Mark Lunt ${ }^{1,2}$, Anthony KP Jones ${ }^{3,4}$, John McBeth $^{1,2}$

\section{Affiliations:}

1. Division of Musculoskeletal and Dermatological Sciences, The University of Manchester, Manchester, UK

2. NIHR Manchester Musculoskeletal Biomedical Research Unit, Manchester Academic Health Science Centre, Manchester, UK

3. Department of Rheumatology, Salford Royal NHS Foundation Trust, Salford, UK

4. Human Pain Research Group, Division of Neuroscience and Experimental Psychology, The University of Manchester, UK

Correspondence: K.J. Mason

Address: $\quad$ BADBIR, Rutherford House (Unit 1), Manchester Science Park, 40 Pencroft Way, Manchester, M15 6SZ

Email: $\quad$ kayleigh.mason@manchester.ac.uk

Telephone: $\quad$ +44 (0) 1613061908

Fax:

+44 (0) 1613061912 


\section{Abstract}

Background and aim: Amplification of sensory signalling within the nervous system along with psychosocial factors contributes to the variation and severity of knee pain. Quantitative Sensory Testing (QST) is a noninvasive test battery that assesses sensory perception of thermal, pressure, mechanical and vibration stimuli used in the assessment of pain. Psychosocial factors also have an important role in explaining the occurrence of pain. The aim was to determine whether QST measures were associated with self-reported pain, and whether those associations were mediated by psychosocial factors.

Methods: Participants with knee pain identified from a population-based cohort completed a tender point count and a reduced QST battery of thermal, mechanical and pressure pain thresholds, temporal summation, mechanical pain sensitivity, dynamic mechanical allodynia and vibration detection threshold performed following the protocol by the German Research Network on Neuropathic Pain. QST assessments were performed at the most painful knee and opposite forearm (if pain-free). Participants were asked to score for their global and knee pain intensities within the past month (range 0 to 10), and complete questionnaire items investigating anxiety, depression, illness perceptions, pain catastrophizing, and physical functioning. QST measures (independent variable) significantly correlated (Spearman's rho) with selfreported pain intensity (dependent variable) were included in structural equation models with psychosocial factors (latent mediators).

Results: 72 participants were recruited with 61 participants (36 women; median age 64 years) with complete data included in subsequent analyses. Tender point count was significantly correlated with global pain intensity. Dynamic mechanical allodynia at the knee and mechanical pain sensitivity at the most painful knee and opposite pain-free forearm were significantly correlated with both global pain and knee pain intensities. Psychosocial factors including pain catastrophising sub-scales (rumination and helplessness) and illness perceptions (consequences and concern) were significant partial mediators of the association with global pain intensity when loaded on to a latent mediator for: tender point count ( $75 \%$ total effect; $95 \%$ confidence interval 22\%, 100\%); mechanical pain sensitivity at the knee (49\%; 12\%, 86\%); and dynamic mechanical allodynia at the knee (63\%; $5 \%, 100 \%)$. Latent psychosocial factors were also significant partial mediators of the association between pain intensity at the tested knee with mechanical pain sensitivity at the knee (30\%; $2 \%, 58 \%)$, but not for dynamic mechanical allodynia at the knee.

Conclusions: Measures of mechanical hyperalgesia at the most painful knee and pain-free opposite forearm were associated with increased knee and global pain indicative of altered central processing. 
Psychosocial factors were significant partial mediators, highlighting the importance of the central integration of emotional processing in pain perception.

Implications: Associations between mechanical hyperalgesia at the forearm and knee, psychosocial factors, and increased levels of clinical global and knee pain intensity provide evidence of altered central processing as a key mechanism in knee pain, with psychological factors playing a key role in the expression of clinical pain.

\section{Highlights}

In people with higher levels of self-reported knee pain, we identified:

- Widespread mechanical hyperalgesia was correlated with greater pain intensity

- Catastrophising and illness perceptions were correlated with greater pain intensity

- Psychosocial factors mediate the relationship between pain and hyperalgesia

- Altered central processing is likely to be a key mechanism in knee pain

\section{Key words}

knee pain; quantitative sensory testing; sensitisation; psychosocial factors; altered central processing 


\section{Abbreviations}

$\begin{array}{ll}\text { BMI } & \text { Body Mass Index } \\ \text { CI } & \text { Confidence Interval } \\ \text { DMA } & \text { Dynamic Mechanical Allodynia } \\ \text { EPIFUND } & \text { Epidemiology of Functional Disorders } \\ \text { HAD } & \text { Hospital Anxiety and Depression scale } \\ \text { ICC } & \text { Intraclass Correlation Coefficient } \\ \text { IPQ-brief } & \text { Brief Illness Perception Questionnaire } \\ \text { IQR } & \text { Interquartile Range } \\ \text { MPS } & \text { Mechanical Pain Sensitivity } \\ \text { OA } & \text { Osteoarthritis } \\ \text { PCS } & \text { Pain Catastrophising Scale } \\ \text { QST } & \text { Quantitative Sensory Testing } \\ \text { RAPA } & \text { Rapid Assessment of Physical Activity } \\ \text { SMD } & \text { Standardised Mean Difference }\end{array}$




\section{Introduction}

Knee pain is a common complaint in the ageing population with an annual prevalence of $25 \%$ in those over $55^{[1]}$. Knee pain may arise through local pathology stimulating the release of inflammatory mediators triggering nociceptive transmission ${ }^{[2]}$. Only moderate correlations exist between knee pain and the structural pathology of osteoarthritis $(\mathrm{OA})$ such as bone marrow lesions, synovitis and subchondral bone oedema, suggesting that altered central processing may be responsible for certain components of chronic pain ${ }^{[3,4]}$. In those with chronic pain, central sensitisation due to-altered central processing through amplifications of somatosensory inputs either via hyperalgesia (hypersensitivity to painful stimuli near a painful site) or allodynia (hypersensitivity to non-painful stimuli near a painful site), and the integration of emotional processing can contribute to the experience of pain in the absence of peripheral damage ${ }^{[5,6]}$; altered central processing is an important mechanism for understanding the discordance between pathological features of $\mathrm{OA}$ and knee pain intensity. Higher reported pain knee intensity is associated with increased sensitivity to temporal summation (repeated noxious stimulation lowering the threshold for nociceptive transmission) in patients with knee OA indicating altered central processing ${ }^{[7,8]}$.

Quantitative sensory testing (QST) is a non-invasive technique used to assess somatosensory functioning ${ }^{[9]}$. There is preliminary evidence to suggest knee OA patients have diminished vibration detection ${ }^{[10]}$ and thermal pain thresholds ${ }^{[11,12]}$ compared with healthy volunteers; however, previous studies have not investigated whether these measures are associated with higher levels of self-reported knee pain intensity. Two recent systematic reviews investigated somatosensory functioning in OA samples. Lluch et al. ${ }^{[13]}$ reported that despite diverse methodologies, increased levels of local hyperalgesia (at the knee, indicating peripheral sensitisation) and widespread hyperalgesia (indicating central sensitisation) were observed for knee OA participants compared with pain-free controls. A meta-analysis by Fingleton et al. ${ }^{[14]}$ demonstrated pressure pain thresholds were significantly lower in patients with knee OA compared with pain-free controls (standardised mean difference [SMD] -0.85; 95\% confidence interval [Cl] -1.1, -0.6), and for knee OA groups with high symptom severity compared with those with low symptom severity (SMD $-0.51 ; 95 \% \mathrm{Cl}-0.73$, 0.30). The authors also identified temporal summation as present in knee OA patients compared with healthy controls, and for knee OA groups with high symptom severity compared with low symptom severity ${ }^{[14]}$. These findings suggest altered central processing is present within a sub-sample of individuals with knee OA and chronic pain.

Recent studies investigating QST in knee OA samples have included measures of psychosocial distress. Cruz-Almeida et al. ${ }^{[15]}$ determined four distinct profiles from psychological and somatosensory measures for 
194 individuals with knee OA using hierarchical cluster analysis with the two most severe clusters reporting the highest levels of pain, anger, depression and mechanical hyperalgesia ${ }^{[15]}$. Findings from Williams et al. ${ }^{[12]}$ and Finan et al. ${ }^{[8]}$ demonstrated higher levels of anxiety and depression in participants with lower grade radiographic disease and moderate to severe knee pain, which were associated with higher levels of disability and widespread hyperalgesia. These results indicate psychosocial factors are associated with altered central processing with low grades of underlying pathology. However, the role of illness perceptions, which have been demonstrated as possible targets for intervention in people with lower back pain ${ }^{[16]}$, have not been addressed in people with knee pain.

The impact of psychosocial factors on the association between self-reported pain intensity and somatosensory functioning has yet to be investigated in a population-based sample of individuals with knee pain. The aim of the present study was to determine whether (i) higher levels of self-reported pain intensity were associated with greater sensitivity to QST measures; (ii) any association between QST measures and pain intensity was mediated by psychosocial factors.

\section{Methods}

\subsection{Participants}

565 participants with knee pain were identified from a prospective population-based cohort investigating chronic pain (the epidemiology of functional disorders [EPIFUND] cohort) ${ }^{[17] . ~ P a r t i c i p a n t s ~ w e r e ~ e l i g i b l e ~ f o r ~}$ this study if they responded to a postal survey, had knee pain, and consented to further contact. It was not possible to robustly identify whether participants in the EPIFUND cohort identified as having knee pain also had underlying OA.

\subsection{Recruitment}

A two-phase telephone recruitment strategy was used: eligible participants were first contacted to verify the presence of knee pain on at least one day in the past month and to consent to the mailing of the participant information sheet about the QST study for their consideration. The second phone call occurred at least 7 days following the first-call to ensure adequate time for delivery and consideration of the information sheet. A more detailed description of the study was provided during the second phone call and if they were interested, participants were invited to attend a 90 minute appointment at a local primary care or research centre. A letter containing details of the study appointment, including the time, date and location, was mailed to each 
participant who agreed to take part. The present study received approval from the National Research Ethics Service Committee North West - Cheshire (12/NW/0556) in order to contact the cohort and complete the study assessments. All participants provided consent at the study visit prior to any assessments.

\subsection{Study Assessments}

All assessments during the study visit were performed by one rater (KJM).

\subsection{Self-reported pain intensity and body mass index (BMI)}

All participants were asked whether they had experienced pain that lasted one day or longer in the past 30 days and to indicate that pain on a blank-body manikin. Participants with knee pain were those who shaded one or both knee regions. Global and knee pain intensities were assessed using 0 to 10 (best to worst) numeric rating scales for the average pain severity experienced within the past 30 days. BMI was calculated from measured weight (kilograms) and height (metres²).

\subsection{Psychosocial Factors}

Participants were provided with a questionnaire, including items addressing anxiety, depression, illness perceptions, pain catastrophising and physical functioning, with a stamped and addressed envelope to mail back to the study team after the assessments were complete. The Hospital Anxiety and Depression (HAD) scale ${ }^{[18]}$ comprises 7 anxiety and 7 depression items (items scored 0 , no symptoms to 3 , strong indication of symptoms; anxiety and depression scales score range $0-21 ; 0$ to 7 classified as normal; 8 to 10 as borderline cases; and $\geq 11$ as cases). The Pain Catastrophizing Scale (PCS) and Brief Illness Perception Questionnaire (IPQ-brief) measured cognitions about pain [19]. The PCS comprises 13 items scored 0 (not at all) to 4 (all of the time) forming three sub-scales: helplessness (6 items, range $0-24$ ), rumination (4 items, range 0-16) and magnification (3 items, range 0-12). The IPQ-brief comprises 8 items scored using a 10point numeric rating scale ${ }^{200]}$; five items (consequences, timeline, personal control, treatment control and identity) address thoughts about the illness, two items (concern and emotion) address the emotional impact and the final item (coherence) relates to the understanding of the illness (pain in the present study). Physical functioning was addressed using the Rapid Assessment of Physical Activity (RAPA) scale. The RAPA includes 9 items (range $0-10$ ) scored "yes" or "no" with 7 items for levels of physical activity ( 0 classified as 
sedentary; 1 to 2 as underactive, 3 to 4 regular underactive, and $\geq 5$ as regular active ( $>5)$, one item for strength (scored 0 or 1 ) and one item for flexibility (scored 0 or 2) [21].

\subsection{Quantitative Sensory Testing}

The QST assessments were performed following the protocol by the German Research Network on Neuropathic Pain [22]. A reduced QST protocol was used; there is limited evidence for the presence of abnormal mechanical or thermal detection thresholds, or paradoxical heat sensations, in knee OA patients. All other assessments were included as these are considered to be altered in those with knee pain (pressure pain; temporal summation) or the literature is conflicting (thermal and mechanical pain, and vibration detection thresholds). QST assessments, except for vibration detection, were performed at the tibial tuberosity of the most painful knee and two centimetres distal to the lateral epicondyle on the opposite forearm (if pain-free): vibration detection was performed on the nearest bony prominences to the test sites in accordance with the QST protocol (at the patella of the most painful knee and the opposite elbow).

\section{Participants who did not achieve a painful sensation during cold or heat pain thresholds were categorised as}

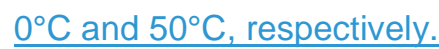

The tender point count was included as a measure of widespread sensitivity to determine whether increased sensitivity to sensory stimuli was localised to the knee or if there was an indication of more generalised changes in pain sensitivity [23]. Participants were provided with standardised descriptions of the QST measures and ratings required; a summary of the test battery is provided in Appendix $A$.

\subsection{Intra-rater reliability}

A convenience sample of 9 volunteers (5 males; median age 25 years; range $22-45$ years) free from musculoskeletal pain completed two reliability sessions 7 days apart to determine intra-rater reliability (assessor KM). One male volunteer could not attend the second session and was not included in the analysis. A tender point examination was completed followed by a reduced QST battery (heat pain; mechanical pain; temporal summation; vibration detection; pressure pain) performed at one knee. Participants were randomised as to which knee was tested for both sessions. Intraclass correlation coefficients (ICC) calculated intra-rater reliability (session 1 compared with session2). ICC could not be determined for tender point counts or cold pain threshold due to 17 and 18 instances, respectively, of 0 scores recorded over the three sessions. ICG were interpreted as none or little correlation $(0.00-0.24)$, low 


\subsection{Sample Size}

In the EPIFUND study [25], the standard deviation of tender point count was 4.5 and of global pain intensity was 2.25, and the regression of global pain intensity on tender point count gave a regression coefficient of 0.16. Entering these values in the $G^{*}$ Power 3.1 .2 software suggest that a sample size of 71 participants would be sufficient to give $80 \%$ power to detect this association at a significance level of 0.05 .

\subsection{Analysis}

The characteristics of study participants, QST measures and psychosocial factors are presented as medians with the interquartile range (IQR) for continuous measures and proportions for categorical variables. Spearman's correlation was used to determine associations between QST measures and psychosocial factors, and QST measures with both self-reported pain intensities. The QST measures (independent variables) with significant correlations $(\mathrm{p}<0.05)$ with one or both measures of self-reported pain intensity (dependent variables) were selected for the mediation model (path c, Figure 1). Psychosocial factors which were significantly correlated $(p<0.05)$ with the QST measures selected as independent variables were selected as mediating variables for the mediation model (path a, Figure 1). Structural equation models with all psychosocial factors associated with each QST measure loading on to a latent mediator were also constructed (Figure 2). Only participants with complete observations for all measures of interest were included in the analyses. All analyses were performed using Stata 13.1 software (Stata, USA).

\section{<Figure 1; Figure 2>}

\section{Results}

\subsection{Participants}

565 of 1530 responders (37\%; median age 60 years; $62 \%$ female) of the EPIFUND cohort reported knee pain; $213(38 \%)$ of those identified with knee pain were contacted during the first telephone recruitment phase (Figure 3). 133 people (24\%) received a study information sheet and 80 people (14\%) either could not 
be contacted, reported no knee pain within the past month, or declined participation. 92 people (16\%) agreed to participate in the study. However, 11 people (2\%) did not attend study appointments and 8 people (1\%) were withdrawn during the study visit. 72 participants (13\%) completed the study. 61 participants (11\%; median age 64 years; 59\% women; Table 1) had complete data for QST measures, psychosocial factors, and self-reported pain intensities, and were included in the analyses. The proportion of female EPIFUND responders with knee pain was comparable to the proportion in this study (62\% and $59 \%$, respectively), although participants in this study were older than the EPIFUND responders (median age 64 years and 60 years, respectively).

\section{$<$ Figure 3>}

\subsection{Participant characteristics}

The median BMI of the 61 participants was 27.7 (IQR 26 to 30.7; Table 1). The medians for self-reported global pain intensity and pain intensity at the tested knee were 5 (IQR 3-7 for both pain intensities). The median for tender point count was 0 (IQR 0 to 2) with no participants meeting the 11 tender point threshold outlined in the 1990 ACR Fibromyalgia criteria [23]. The median ratios for temporal summation at the knee and forearm exceeded 1 ( 2 and 1.9, respectively) indicating greater pain was reported in response to the train of mechanical stimuli compared with the single stimulus. Apart from the median scores for DMA (which were identical at both test sites), the median thresholds for cold pain, MPS and vibration detection were higher at the forearm than the knee. The median thresholds for heat and pressure pain were lower at the forearm than the knee.

The median scores for the HAD anxiety (3; IQR 1 to 6 ) and depression (5; IQR 2 to 8 ) sub-scales were below the score for borderline cases (0-7 normal; 8-10 borderline case; 11-21 case). In the present study, 12 borderline and 7 cases of anxiety, and 8 borderline and 3 cases of depression were identified using the HAD sub-scale cut-offs (Table 2) [18]. Median scores of 3 (IQR 1 to 2), 1 (IQR 1 to 3 ) and 3 (IQR 2 to 5) were reported for the rumination, magnification and helplessness sub-scales of the PCS, respectively. The median scores for items of the IPQ-Brief were: consequences (3; IQR 2 to 5); timeline (8; IQR 4 to 10; inversely scored); personal control (5; IQR 3 to 7; inversely scored); treatment control (5; IQR 2 to 7 ; inversely scored); identity (2; IQR 1 to 4); concern (4; IQR 2 to 7); coherence (2; IQR 1 to 5); emotion (3; IQR 1 to 4). A median score of 4 (regular underactive; IQR 4 to 5) was observed for the RAPA. 


\subsection{Correlations between QST measures and self-reported pain intensity}

There were significant positive correlations ( $p<0.05$; Table 3 ) between global pain intensity and number of tender points, knee and forearm MPS, and DMA at the knee. Knee and forearm MPS, and DMA at the knee were also significantly positively correlated with higher pain intensity at the tested knee.

\section{$<$ Table 3>}

\subsection{Correlations between QST measures and psychosocial factors}

In total, 10 psychosocial factors were significantly correlated $(p<0.05$; Table 4$)$ with tender point count; seven factors were significantly correlated with knee MPS; nine factors were significantly correlated with DMA at the knee; and 5 factors were significantly correlated with MPS at the forearm. Impact of illness on life, increased illness duration and higher levels of concern (illness perceptions) and magnification (pain catastrophizing) were all significantly positively correlated with tender point count, mechanical pain sensitivity at the knee and forearm, and dynamic mechanical allodynia at the knee.

\section{$<$ Table 4>}

\subsection{Mediation Analysis}

Nine significant partial mediators of the associations between QST measures and the self-reported global and knee pain intensity measures were identified (Table 5). The total effect of tender point count on global pain intensity was 0.467 ( $\beta$-coefficient; $95 \% \mathrm{Cl} 0.184,0.749$; Table 5). Within the mediation model, the direct effect (path c; Figure 1) between tender point count and global pain intensity was non-significant $(\beta 0.467$; $95 \% \mathrm{Cl}-0.086,0.462$ ). The indirect effect (path a x path b; Figure $1 ; \beta 0.279 ; 95 \% \mathrm{Cl} 0.093,0.465$ ) between tender point count and concern item of the IPQ-brief (path a), and between concern and global pain intensity (path b) was significant. The proportion of the total mediated effect was determined by dividing the $\beta$ coefficient for the indirect effect by the $\beta$-coefficient for the total effect $(0.279 / 0.467=60 \%)$.

The association between increased number of tender points and increased global pain intensity was also significantly partially mediated by the consequences item of the IPQ-brief, and the helplessness and rumination sub-scales of the PCS explaining $57 \%, 56 \%$ and $34 \%$ of the total effect, respectively. 
Increased knee MPS and increased global pain intensity was partially mediated by concern, consequences and helplessness explaining $45 \%, 40 \%$ and $40 \%$ of the total effect respectively, and increased knee MPS and increased pain intensity at the tested knee were partially mediated by consequences and concern, explaining $30 \%$ and $29 \%$ of the total effect respectively.

\section{$<$ Table 5>}

The inclusion of psychosocial factors loaded on to a latent mediator rather than individual items (Figure 2) accounted for $75 \%, 52 \%, 63 \%$ and $35 \%$ of the total effect of tender point, knee MPS and knee DMA on global pain intensity, and knee MPS on knee pain intensity, respectively (Table 6). However, the latent psychosocial mediator was not a partial mediator of the association between knee DMA on knee pain intensity (30\% total effect mediated; Table 6).

\section{$<$ Table 6>}

\section{Discussion}

The present study identified significant associations between greater levels of self-reported pain intensity (globally and at the knee) with measures of mechanical hyperalgesia (greater number of tender points, and increased MPS and DMA). The identification of widespread mechanical hyperalgesia (global pain intensity significantly associated with tender point count and forearm MPS) suggests that generalised alterations in central pain processing (an aspect of central sensitisation) contributes to mechanisms of knee pain. The associations between self-reported pain intensity and mechanical hyperalgesia were also explained in part by psychosocial factors, namely illness perceptions, suggests central integration of these phenomena and altered somatosensory processing in those with knee pain.

The present study demonstrated mechanical hyperalgesia (tender points, mechanical pain sensitivity and dynamic mechanical allodynia) at the knee and forearm were associated with greater levels of self-reported pain intensity, but that pain thresholds (heat, cold, mechanical and pressure) and temporal summation at the same sites were not. Previous studies have identified associations between the presence of temporal summation in knee OA samples compared with healthy controls, and between knee OA groups with high symptom severity compared with low symptom severity ${ }^{[7,26]}$. Within-person associations between increased pain severity and measures of pressure pain and temporal summation have been identified in one study [27]; however, the sample size was much larger $(n=2126)$ and the temporal summation methodology applied for a longer time period (30 seconds), which may account for the lack of association in in the present study. 
While previous studies have shown somatosensory disturbances in samples with knee pain compared to pain-free controls, a recent population-based study of individuals with knee OA classified according to the median number of disease-related symptoms and a group of pain-free controls demonstrated no differences across the groups for the warm detection, heat pain, or heat pain tolerance thresholds at the knee or forearm, or for cold pain and cold pain tolerance thresholds at the right hand suggesting that peripheral somatosensory disturbances were not present in the knee OA groups ${ }^{[26]}$. However, significantly higher levels of pain intensity were reported for all QST assessments and at all test sites for the high and (to a lesser extent) low symptom count knee OA groups compared with controls ${ }^{[26]}$. These findings suggest the presence of amplification of somatosensory inputs within the central nervous system in those with knee pain. A study by Neogi et al. posits that sensitisation is a trait already present with patients with knee $O A$ and is not a consequence of joint pathology [27]: the authors did not observe associations between the duration, presence or severity of radiographic knee OA with increased sensitivity to pressure pain and mechanical temporal summation suggesting the presence of central sensitisation in their sample. The present study supports this finding as mechanical hyperalgesia at the forearm, a pain-free site opposite to the most painful knee, and a greater number of tender points were significantly associated with higher levels of global pain intensity suggesting the presence of altered central processing.

Only one previous study reported pain catastrophizing as a significant partial mediator of the association between female sex and higher levels of self-reported pain intensity, disability and pain behaviour modelled as a latent pain-related outcome measure in 168 subjects with knee $\mathrm{OA}$; these findings indicate women are more likely to report pain, and catastrophizing explains a proportion of that association ${ }^{[28]}$. However, the study did not perform QST assessments ${ }^{[28]}$. The present study identified measures of catastrophizing along with illness perceptions as partial mediators of the association between QST measures and self-reported pain intensity demonstrating the role of central emotional processing in mediating increasing central pain processing.

Previous studies have demonstrated differences in sensory perception thresholds between participants with

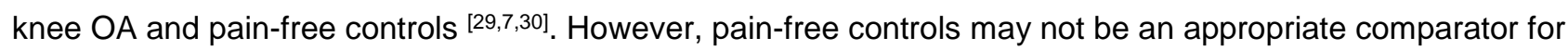
people with chronic pain. Psychosocial factors such as depression, anxiety, pain catastrophizing and lowered physical functioning that influence pain perception occur less frequently in pain-free controls. Other studies have stratified knee OA patients by disease [12], symptom [26], or pain severity ${ }^{[8,7]}$, or have used patients with inflammatory arthritis as a comparator group [31,32]. A meta-analysis demonstrated significantly lower pressure pain thresholds in those with knee OA compared with pain-free controls and for knee OA 
groups with high symptom severity compared with those with low symptom severity ${ }^{[14]}$. The present study used a pain-free test site on the opposite side of the body to the most painful knee to eliminate person-level confounding as all control assessments were performed within-person; consequently, within-person mechanical hyperalgesia along with measures of pain catastrophising and illness perceptions were identified as indicators of greater self-reported pain intensity, suggesting that altered central pain processing contributes to mechanisms of knee pain.

A limitation of the present study is the cross-sectional study design. While insights into the associations between QST measures, pain and psychosocial factors have been provided, it is unknown whether mechanical hyperalgesia or illness perceptions are causal or a consequence of having pain. Another limitation is that the present study was underpowered to fully explore the role of age and sex as moderators of the associations between QST measures and self-reported pain intensity; Bartley et al. ${ }^{[33]}$ demonstrated increased sensitivity to QST measures (cold pressor; mechanical pain; pressure pain) in 183 females compared with 105 males with symptomatic knee OA, despite similar mean values recorded for the WOMAC (34.5 \pm 20.5 for females; $34.1 \pm 20.7$ for males). The authors did observe significantly wider distributions of pain sites in females $(6.0 \pm 4.7$ vs $4.3 \pm 3.2)$, which may suggest altered central processing contributing to increased sensitivity in females ${ }^{[33]}$.

A further limitation is the numeric rating scale used to determine global and knee pain intensity levels in the past month in participants; pain intensity in the past month was not associated with current somatosensory thresholds. Previous studies have demonstrated significant associations between pain thresholds and pain in the previous 24 hours ${ }^{[7,34]}$ and current pain ${ }^{[26,35]}$. The inclusion of multiple measures of current and recent knee and/or global pain intensities in future studies exploring current somatosensory functioning should be considered.

\section{Conclusions}

The present study emphasises the contributions of altered central processing and integration of psychosocial factors in the experience of knee pain. Few existing treatments are effective in reducing pain intensity in those with chronic pain in the long term [36]; improving our understanding of the mechanisms driving chronic pain provides new or alternative targets for intervention. The findings of the present study may help to explain inter-individual differences in pain reporting and underscores the role of psychosocial factors in pain research, particularly when investigating variations in the effectiveness of interventions for chronic pain. 


\section{Implications}

Associations between mechanical hyperalgesia at the forearm and knee, psychosocial factors, and increased levels of clinical global and knee pain intensity provide evidence of altered central processing as a key mechanism in knee pain with psychological factors playing a key role in the expression of self-reported pain.

\section{Acknowledgements}

The authors express their gratitude to all study participants, Bollington Health and Leisure and NIHR Wellcome Trust Manchester Clinical Research Facility, and to members of the Pain Across the Adult Lifespan study team (James Anderson; Claire Bennett; Dr Deborah Brown; Rosie Duncan; Dr Matthew Mulvey; Dr Amir Rashid).

\section{Funding}

Arthritis Research UK programme grant 17552. This report includes independent research supported by (or funded by) the National Institute for Health Research Biomedical Research Unit Funding Scheme. The views expressed in this publication are those of the author(s) and not necessarily those of the NHS, the National Institute for Health Research or the Department of Health.

\section{Disclosures}

KJM received honoraria for developing and delivering an educational presentation for Janssen-Cilag Ltd and Eli Lilly Ltd. AKPJ is National PI on a drug trial supported by Daichi-Sankyo. The other authors (ML; TON; JM) have no conflicts of interest, including relevant financial interests, activities, relationships, and affiliations.

\section{Ethical Issues}

The present study received approval from the National Research Ethics Service Committee North West Cheshire (12/NW/0556) in order to contact the cohort and complete the study assessments. All participants 
provided consent at the study visit prior to any assessments. Participants were anonymised to maintain their 1 privacy.

2

3

4

5

7

8

9

10

11

12

13

14

15

16

17

18

19

20

21

22

23

24

25

26

27

28

29

30

31

32

33

34

35

36

37

38

39

40

41

42

43

44

45

46

47

48

49

50

51

52

53

54

55

56

57

58

59

60

61

62

63 


\section{References}

[1] Peat G, McCarney R, Croft P. Knee pain and osteoarthritis in older adults: a review of community burden and current use of primary health care. Annals of the Rheumatic Diseases 2001; 60:91-97

[2] Liu-Bryan R, Terkeltaub R. Emerging regulators of the inflammatory process in osteoarthritis. Nat Rev Rheumatol 2015; 11:35-44

[3] Brown CA, El-Deredy W, Jones AK. When the brain expects pain: common neural responses to pain anticipation are related to clinical pain and distress in fibromyalgia and osteoarthritis. European Journal of Neuroscience 2014; 39:663-672

[4] Barr AJ, Campbell TM, Hopkinson D, Kingsbury SR, Bowes MA, Conaghan PG. A systematic review of the relationship between subchondral bone features, pain and structural pathology in peripheral joint osteoarthritis. Arthritis Res Ther 2015; 17:228

[5] Kidd BL, Photiou A, Inglis JJ. The role of inflammatory mediators on nociception and pain in arthritis. Novartis Found Symp 2004; 260:122-133

[6] Woolf CJ. Central sensitization: Implications for the diagnosis and treatment of pain. Pain 2010

[7] Arendt-Nielsen L, Nie H, Laursen MB, Laursen BS, Madeleine P, Simonsen OH, Graven-Nielsen T. Sensitization in patients with painful knee osteoarthritis. Pain 2010; 149:573-581

[8] Finan PH, Buenaver LF, Bounds SC, Hussain S, Park RJ, Haque UJ, Campbell CM, Haythornthwaite JA, Edwards RR, Smith MT. Discordance between pain and radiographic severity in knee osteoarthritis: findings from quantitative sensory testing of central sensitization. Arthritis and Rheumatism 2013; 65:363-372

[9] Shy ME, Frohman EM, So YT, Arezzo JC, Cornblath DR, Giuliani MJ, Kincaid JC, Ochoa JL, Parry GJ, Weimer LH. Quantitative sensory testing. Neurology 2003; 60:898-904

[10] Shakoor N, Agrawal A, Block JA. Reduced lower extremity vibratory perception in osteoarthritis of the knee. Arthritis Care \& Research 2008; 59:117-121

[11] Martinez V, Fletcher D, Bouhassira D, Sessler DI, Chauvin M. The Evolution of Primary Hyperalgesia in Orthopedic Surgery: Quantitative Sensory Testing and Clinical Evaluation Before and After Total Knee Arthroplasty. Anesthesia \& Analgesia 2007; 105:815-821

[12] Williams DA, Farrell MJ, Cunningham J, Gracely RH, Ambrose K, Cupps T, Mohan N, Clauw DJ. Knee pain and radiographic osteoarthritis interact in the prediction of levels of self-reported disability. Arthritis and Rheumatism 2004; 51:558-561

[13] Lluch E, Torres R, Nijs J, Van OJ. Evidence for central sensitization in patients with osteoarthritis pain: a systematic literature review. Eur J Pain 2014; 18:1367-1375

[14] Fingleton C, Smart K, Moloney N, Fullen BM, Doody C. Pain sensitization in people with knee osteoarthritis: a systematic review and meta-analysis. Osteoarthritis Cartilage 2015; 23:1043-1056

[15] Cruz-Almeida Y, King CD, Goodin BR, Sibille KT, Glover TL, Riley JL, Sotolongo A, Herbert MS, Schmidt J, Fessler BJ, Redden DT, Staud R, Bradley LA, Fillingim RB. Psychological profiles and pain characteristics of older adults with knee osteoarthritis. Arthritis Care Res (Hoboken ) 2013; 65:1786-1794 
[16] Glattacker M, Heyduck K, Meffert C. Illness beliefs, treatment beliefs and information needs as starting points for patient information--evaluation of an intervention for patients with chronic back pain. Patient Education and Counseling 2012; 86:378-389

[17] Chiu YH, Silman AJ, Macfarlane GJ, Ray D, Gupta A, Dickens C, Morriss R, McBeth J. Poor sleep and depression are independently associated with a reduced pain threshold. Results of a population based study. Pain 2005; 115:316-321

[18] Zigmond AS, Snaith RP. The hospital anxiety and depression scale. Acta Psychiatrica Scandinavica 1983; 67:361-370

[19] Sullivan MJL, Bishop SR, Pivik J. The pain catastrophizing scale: Development and validation. Psychological assessment 1995; 7:524

[20] Broadbent E, Petrie KJ, Main J, Weinman J. The brief illness perception questionnaire. Journal of Psychosomatic Research 2006; 60:631-637

[21] Topolski TD, LoGerfo J, Patrick DL, Williams B, Walwick J, Patrick MB. The Rapid Assessment of Physical Activity (RAPA) among older adults. Preventing chronic disease 2006; 3:A118

[22] Rolke R, Magerl W, Campbell KA, Schalber C, Caspari S, Birklein F, Treede RD. Quantitative sensory testing: a comprehensive protocol for clinical trials. Eur J Pain 2006; 10:77-88

[23] Wolfe F, Smythe HA, Yunus MB, Bennett RM, Bombardier C, Goldenberg DL, Tugwell P, Campbell SM, Abeles M, Clark P, . The American College of Rheumatology 1990 Criteria for the Classification of Fibromyalgia. Report of the Multicenter Criteria Committee. Arthritis and Rheumatism 1990; 33:160-172

[24] Wylde V, Palmer S, Learmonth ID, Dieppe P. Test-retest reliability of Quantitative Sensory Testing in knee osteoarthritis and healthy participants. Osteoarthritis and Cartilage 2011; 19:655-658

[25] Brown D, Mulvey M, Cordingley L, Rashid A, Horan M, Pendleton N, Duncan R, McBeth J. The relationship between psychological distress and multiple tender points across the adult lifespan. Arch Gerontol Geriatr 2016; 63:102-107

[26] King CD, Sibille KT, Goodin BR, Cruz-Almeida Y, Glover TL, Bartley E, Riley JL, Herbert MS, Sotolongo A, Schmidt J, Fessler BJ, Redden DT, Staud R, Bradley LA, Fillingim RB. Experimental pain sensitivity differs as a function of clinical pain severity in symptomatic knee osteoarthritis. Osteoarthritis Cartilage 2013; 21:1243-1252

[27] Neogi T, Frey-Law L, Scholz J, Niu J, Arendt-Nielsen L, Woolf C, Nevitt M, Bradley L, Felson DT, for the Multicenter Osteoarthritis (MOST) Study. Sensitivity and sensitisation in relation to pain severity in knee osteoarthritis: trait or state? Annals of the Rheumatic Diseases 2013; DOI: 10.1136/annrheumdis-2013-204191:

[28] Keefe FJ, Lefebvre JC, Egert JR, Affleck G, Sullivan MJ, Caldwell DS. The relationship of gender to pain, pain behavior, and disability in osteoarthritis patients: the role of catastrophizing. Pain 2000; 87:325-334

[29] Imamura M, Imamura ST, Kaziyama HH, Targino RA, Hsing WT, de Souza LP, Cutait MM, Fregni F, Camanho GL. Impact of nervous system hyperalgesia on pain, disability, and quality of life in patients with knee osteoarthritis: a controlled analysis. Arthritis and Rheumatism 2008; 59:14241431 
[30] Wylde V, Palmer S, Learmonth ID, Dieppe P. Somatosensory abnormalities in knee OA. Rheumatology 2012; 51:535-543

[31] Gerecz-Simon EM, Tunks ER, Heale JA, Kean WF, Buchanan WW. Measurement of pain threshold in patients with rheumatoid arthritis, osteoarthritis, ankylosing spondylitis, and healthy controls. Clinical Rheumatology 1989; 8:467-474

[32] Hendiani JA, Westlund KN, Lawand N, Goel N, Lisse J, McNearney T. Mechanical sensation and pain thresholds in patients with chronic arthropathies. The Journal of Pain 2003; 4:203-211

[33] Bartley EJ, King CD, Sibille KT, Cruz-Almeida Y, Riley JL, III, Glover TL, Goodin BR, Sotolongo AS, Herbert MS, Bulls HW, Staud R, Fessler BJ, Redden DT, Bradley LA, Fillingim RB. Enhanced Pain Sensitivity Among Individuals With Symptomatic Knee Osteoarthritis: Potential Sex Differences in Central Sensitization. Arthritis Care Res (Hoboken ) 2016; 68:472-480

[34] Skou ST, Graven-Nielsen T, Lengsoe L, Simonsen O, Laursen MB, Arendt-Nielsen L. Relating clinical measures of pain with experimentally assessed pain mechanisms in patients with knee osteoarthritis. Scandinavian Journal of Pain 2013; 4:111-117

[35] Skou ST, Graven-Nielsen T, Rasmussen S, Simonsen OH, Laursen MB, Arendt-Nielsen L. Widespread sensitization in patients with chronic pain after revision total knee arthroplasty. Pain 2013; 154:1588-1594

[36] Eccleston C, Morley SJ, Williams AC. Psychological approaches to chronic pain management: evidence and challenges. British Journal of Anaesthesia 2013; 111:59-63 
Figure 1 Mediation model

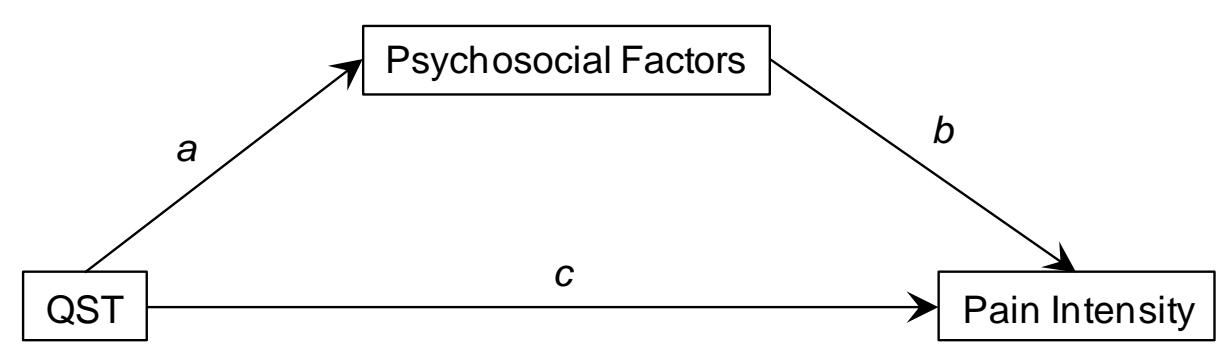

The direct effect is represented by path $\mathrm{c}$ between the independent and dependent variables. The indirect path is represented by path a between the independent and mediator variables, and path $b$ between the mediator and dependent variables. 
Figure 2 Mediation model including latent psychosocial mediating variable

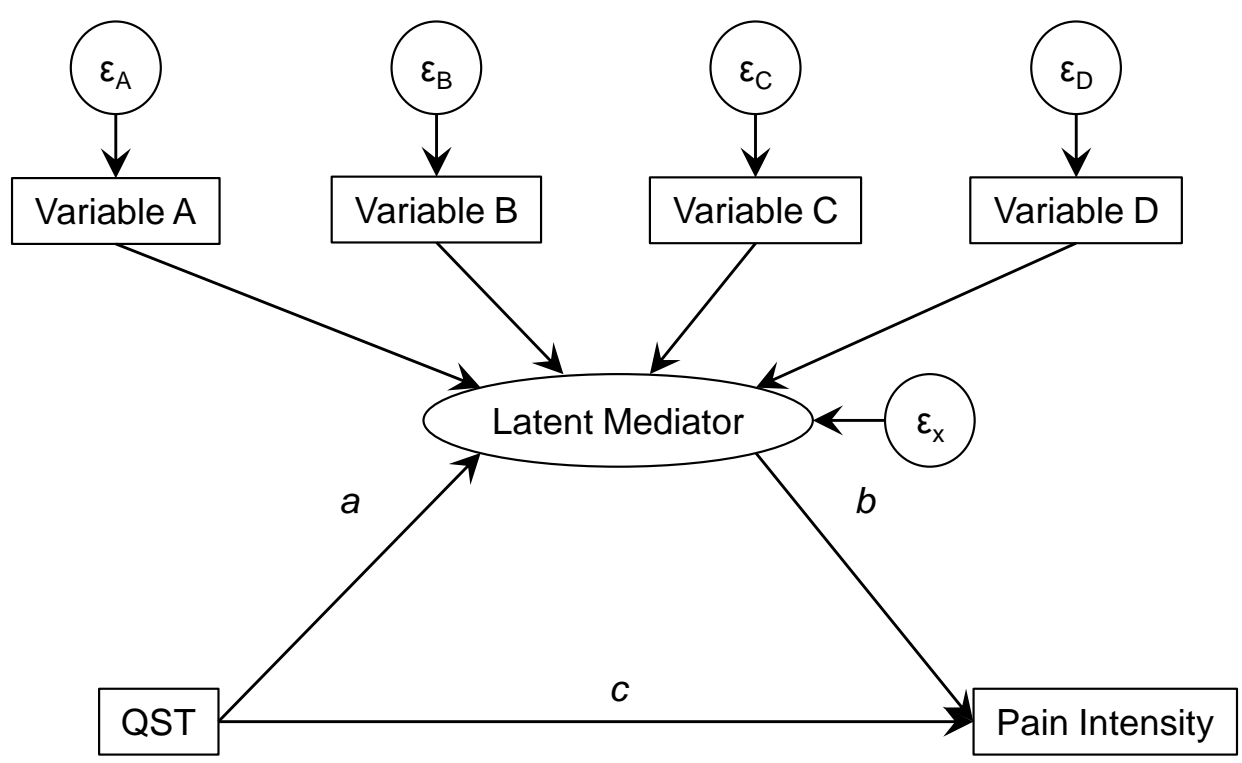

Path c represents the direct effect between the independent and dependent variables. Paths $a$ and $b$ represent the indirect path between the independent and mediator variables (path a), and between the mediator and dependent variables (path b).

$\varepsilon=$ error term; QST = quantitative sensory testing. 
Figure 3 Recruitment flowchart

1
565 identified with knee pain

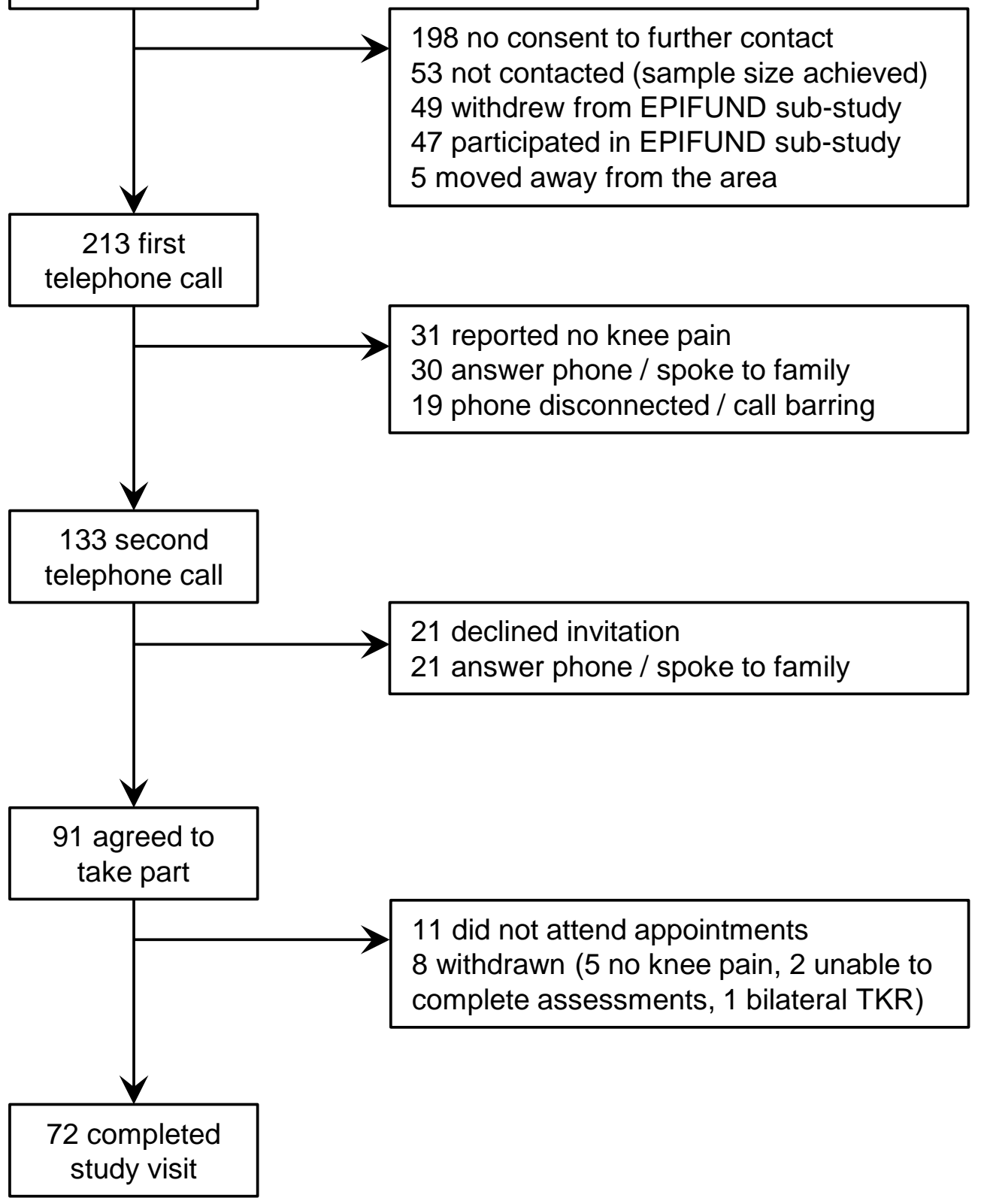


Table 1 Participant characteristics: self-reported pain and QST measures

\begin{tabular}{|c|c|}
\hline Variable (observed range) & $\mathrm{N}=61$ \\
\hline Females (\%) & $36(59.0 \%)$ \\
\hline Age (years; median (IQR)) & 64 (56 to 69$)$ \\
\hline BMI (kg/m2; median (IQR)) & 27.7 (26 to 30.7$)$ \\
\hline \multicolumn{2}{|l|}{ Outcome Measures } \\
\hline Global pain intensity (0 to $10 \mathrm{NRS}$ ) & 5 (3 to 7$)$ \\
\hline Tested knee pain intensity (0 to $10 \mathrm{NRS}$ ) & 5 (3 to 7$)$ \\
\hline \multicolumn{2}{|l|}{ Central QST } \\
\hline Tender point (0 to 18$)$ & $0(0$ to 2$)$ \\
\hline Knee temporal summation $(\geq 1)$ & $1(0.8$ to 1.48$)$ \\
\hline Forearm temporal summation $(\geq 1)$ & $2(1.42$ to 2.67$)$ \\
\hline \multicolumn{2}{|l|}{ Knee QST } \\
\hline Cold pain $\left(0\right.$ to $\left.32.0^{\circ} \mathrm{C}\right)$ & $0(0$ to 0.8$)$ \\
\hline Heat pain $\left(32.0\right.$ to $\left.50^{\circ} \mathrm{C}\right)$ & $48.33(45.3$ to 50$)$ \\
\hline Mechanical pain ( 0 to $512 \mathrm{mN}$ ) & $90.51(42.22$ to 174.18$)$ \\
\hline MPS (0 to $100 \mathrm{NRS}$ ) & 2.49 (0.86 to 5.97$)$ \\
\hline DMA (0 to $100 \mathrm{NRS}$ ) & $0(0$ to 1$)$ \\
\hline Vibration (0 to 8$)$ & 4.33 (3.33 to 5.33$)$ \\
\hline Pressure pain $(0$ to $10 \mathrm{~kg} / \mathrm{cm} 2)$ & $5.6(3.4$ to 7.3$)$ \\
\hline \multicolumn{2}{|l|}{ Forearm QST } \\
\hline Cold pain $\left(0\right.$ to $\left.32.0^{\circ} \mathrm{C}\right)$ & $1.3(0$ to 14.3$)$ \\
\hline Heat pain $\left(32.0\right.$ to $\left.50^{\circ} \mathrm{C}\right)$ & 47.03 (45.1 to 48.57$)$ \\
\hline Mechanical pain (0 to $512 \mathrm{mN}$ ) & 45.25 (21.11 to 105$)$ \\
\hline MPS (0 to $100 \mathrm{NRS}$ ) & 2.97 (0.94 to 7.17$)$ \\
\hline DMA (0 to $100 \mathrm{NRS}$ ) & $0(0$ to 0.2$)$ \\
\hline Vibration (0 to 8 ) & $6(5.33$ to 6.67$)$ \\
\hline Pressure pain $(0$ to $10 \mathrm{~kg} / \mathrm{cm} 2)$ & 3.67 (2.57 to 5.13 ) \\
\hline
\end{tabular}

$\mathrm{IQR}=$ interquartile range; NRS = numeric rating scale; $\mathrm{CPT}=$ cold pain threshold; HPT = heat pain threshold; $\mathrm{MPT}=$ mechanical pain threshold; $\mathrm{mN}$ = milli-Newton; MPS = mechanical pain sensitivity; DMA = dynamic mechanical allodynia; VDT = vibration detection threshold; PPT = pressure pain threshold. 
Table 2 Participant characteristics: psychosocial factors

\begin{tabular}{|c|c|}
\hline Variable (observed range) & Median (IQR) \\
\hline \multicolumn{2}{|l|}{ HAD (0 to 21 sub-scale) } \\
\hline Anxiety & 5 (2 to 8$)$ \\
\hline Depression & 3 (1 to 6$)$ \\
\hline \multicolumn{2}{|l|}{ PCS } \\
\hline Rumination (4 items; 0 to 16 ) & $3(1$ to 5$)$ \\
\hline Magnification (3 items; 0 to 12 ) & 1 (1 to 3$)$ \\
\hline Helplessness (6 items; 0 to 24 ) & $3(2$ to 5$)$ \\
\hline \multicolumn{2}{|l|}{ IPQ-brief (0 to 10 NRS per item) } \\
\hline Consequences & $3(2$ to 5$)$ \\
\hline Timeline & $8(4$ to 10$)$ \\
\hline Personal Control & 5 (3 to 7$)$ \\
\hline Treatment Control & 5 (2 to 7$)$ \\
\hline Identity & $2(1$ to 4$)$ \\
\hline Concern & $4(2$ to 7$)$ \\
\hline Coherence & $2(1$ to 5$)$ \\
\hline Emotion & $3(1$ to 4$)$ \\
\hline \multicolumn{2}{|l|}{ Physical Functioning } \\
\hline RAPA (7 items; 0 to 7 ) & $4(4$ to 5$)$ \\
\hline
\end{tabular}

$\mathrm{HAD}=$ Hospital Anxiety and Depression Scale; PCS = Pain Catastrophizing Scale; IPQ-brief = IIIness Perception Questionnaire Brief; RAPA $=$ Rapid Assessment of Physical Activity. 
Table 3 Association between self-reported pain intensity and QST measures

1

2

3

4

5

6

7

8

9

10

11

12

13

14

15

16

17

18

19

20

21

22

23

24

25

26

27

28

29

30

31

32

33

34

35

36

37

38

39

40

41

42

43

44

45

46

47

48

49

50

51

52

53

54

55

56

57

58

59

60

61

62

63

64

65

\begin{tabular}{rcc} 
& \multicolumn{2}{c}{ Pain Intensity (NRS) } \\
\cline { 2 - 3 } & Global & Tested knee \\
\hline Central QST & & \\
\hline Tender point & $\mathbf{0 . 3 3 6 4}$ & 0.1811 \\
Knee TS & -0.0608 & -0.1034 \\
Forearm TS & 0.0970 & 0.1433 \\
\hline Knee QST & & \\
\hline CPT & 0.1948 & 0.2430 \\
HPT & -0.0731 & 0.0153 \\
MPT & 0.0844 & 0.1146 \\
MPS & $\mathbf{0 . 3 3 6 6}$ & $\mathbf{0 . 3 3 5 0}$ \\
DMA & $\mathbf{0 . 3 3 3 6}$ & $\mathbf{0 . 4 3 5 8}$ \\
VDT & 0.0169 & -0.0929 \\
PPT & -0.2211 & -0.1443 \\
\hline Forearm QST & & \\
\hline CPT & -0.0760 & -0.0396 \\
HPT & -0.1429 & -0.0385 \\
MPT & -0.0364 & -0.0379 \\
MPS & $\mathbf{0 . 3 3 1 9}$ & $\mathbf{0 . 3 3 3 3}$ \\
DMA & 0.2413 & 0.1949 \\
VDT & -0.0049 & -0.1158 \\
PPT & -0.1852 & -0.1183 \\
\hline
\end{tabular}

$p<0.05$ for values in bold; ${ }^{*} p<0.0029$ (0.05/17; Bonferroni Correction).

$\mathrm{NRS}=$ numeric rating scale; TS = temporal summation; $\mathrm{CPT}=$ cold pain threshold; HPT $=$ heat pain threshold; MPT $=$ mechanical pain threshold; MPS = mechanical pain sensitivity; DMA = dynamic mechanical allodynia; VDT = vibration detection threshold; PPT = pressure pain threshold. 
Table 4 Association between QST measures and psychosocial factors

\begin{tabular}{rcccc} 
& TPC & Knee MPS & Knee DMA & Forearm MPS \\
\hline HAD & & & & \\
Anxiety & 0.117 & 0.1251 & 0.2332 & 0.0498 \\
Depression & 0.178 & 0.1539 & $\mathbf{0 . 2 9 9 4}$ & 0.0275 \\
\hline PCS & & & & \\
\hline Rumination & $\mathbf{0 . 2 6 5}$ & 0.2117 & $\mathbf{0 . 3 1 2 0}$ & 0.1165 \\
Magnification & $\mathbf{0 . 4 0 1 ^ { \star }}$ & $\mathbf{0 . 3 3 7 4}$ & $\mathbf{0 . 3 5 5 0}$ & $\mathbf{0 . 2 8 5 0}$ \\
Helplessness & $\mathbf{0 . 3 3 0}$ & $\mathbf{0 . 3 9 4 6 ^ { \star }}$ & $\mathbf{0 . 3 5 4 8}$ & 0.2259 \\
\hline IPQ-brief & & & & \\
\hline Consequences & $\mathbf{0 . 4 5 2 ^ { \star }}$ & $\mathbf{0 . 3 8 3 3 ^ { \star }}$ & $\mathbf{0 . 3 2 3 7}$ & $\mathbf{0 . 2 8 3 9}$ \\
Timeline & $\mathbf{0 . 3 2 3}$ & $\mathbf{0 . 3 8 2 0 ^ { \star }}$ & $\mathbf{0 . 2 7 7 8}$ & $\mathbf{0 . 2 7 0 0}$ \\
Personal control & -0.125 & 0.0885 & 0.1257 & 0.0255 \\
Treatment control & -0.230 & -0.1237 & 0.0348 & $-\mathbf{0 . 3 0 0 2}$ \\
Identity & $\mathbf{0 . 4 3 3 ^ { \star }}$ & $\mathbf{0 . 2 7 7 7}$ & 0.1980 & 0.2361 \\
Concern & $\mathbf{0 . 4 4 5 ^ { \star }}$ & $\mathbf{0 . 3 6 7 6}{ }^{\star}$ & $\mathbf{0 . 2 8 0 1}$ & $\mathbf{0 . 2 9 1 1}$ \\
Coherence & -0.196 & 0.0029 & -0.1074 & 0.0577 \\
Emotion & $\mathbf{0 . 4 0 6}$ & $\mathbf{0 . 3 1 8 5}$ & $\mathbf{0 . 3 3 9 1}$ & 0.1652 \\
\hline Rhysical Functioning & & & & \\
\hline RAPA & $\mathbf{- 0 . 3 1 1}$ & -0.1339 & -0.0600 & -0.0839 \\
\hline
\end{tabular}

TPC = tender point count; MPS = mechanical pain sensitivity; DMA = dynamic mechanical allodynia; $\mathrm{HAD}=$ Hospital Anxiety and Depression Scale; PCS = Pain Catastrophizing Scale; IPQ-brief = Illness Perception Questionnaire Brief; RAPA = Rapid Assessment of Physical Activity. 
Table 5 Effect of psychosocial factors on the association between pain intensity and QST measures

Proportion of Total Effect Mediated $(95 \% \mathrm{Cl})$

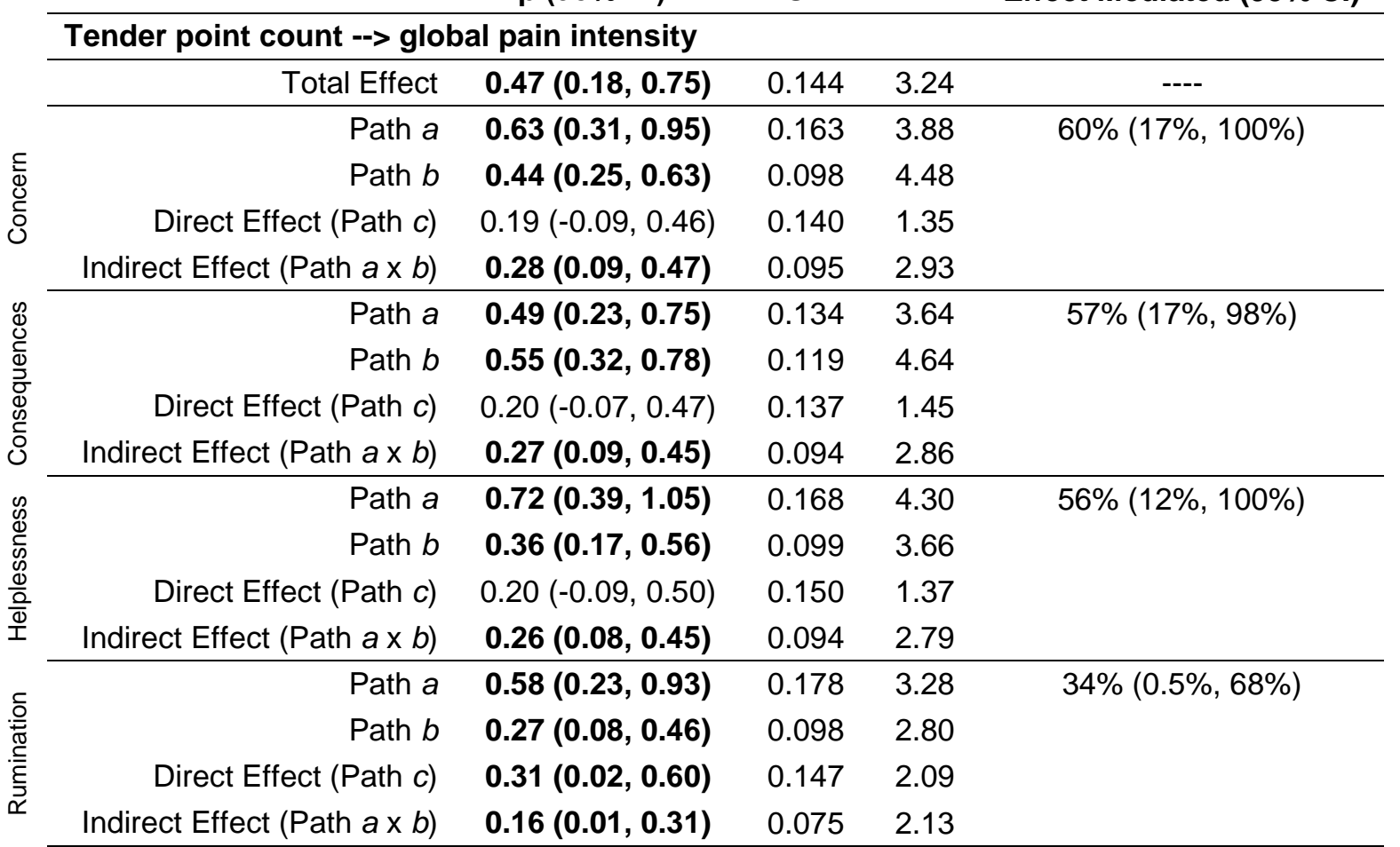

Knee MPS --> global pain intensity

\begin{tabular}{|c|c|c|c|c|}
\hline Total Effect & $0.12(0.05,0.20)$ & 0.038 & 3.26 & ---- \\
\hline Path $a$ & $0.13(0.04,0.22)$ & 0.045 & 2.79 & $45 \%(11 \%, 79 \%)$ \\
\hline Path $b$ & $0.44(0.26,0.62)$ & 0.092 & 4.76 & \\
\hline Direct Effect (Path $c)$ & $0.07(0.00,0.14)$ & 0.035 & 1.99 & \\
\hline Indirect Effect (Path $a \times b)$ & $0.06(0.01,0.10)$ & 0.023 & 2.41 & \\
\hline Path $a$ & $0.09(0.02,0.17)$ & 0.037 & 2.44 & $40 \%(8 \%, 73 \%)$ \\
\hline Path $b$ & $0.55(0.33,0.77)$ & 0.110 & 4.99 & \\
\hline Direct Effect (Path $c$ ) & $0.07(0.01,0.14)$ & 0.034 & 2.2 & \\
\hline Indirect Effect (Path $a \times b)$ & $0.05(0.01,0.10)$ & 0.023 & 2.19 & \\
\hline Path $a$ & $0.13(0.04,0.23)$ & 0.048 & 2.81 & $40 \%(6 \%, 73 \%)$ \\
\hline Path $b$ & $0.37(0.19,0.54)$ & 0.091 & 4.03 & \\
\hline Direct Effect (Path $c$ ) & $0.08(0.01,0.15)$ & 0.036 & 2.09 & \\
\hline Indirect Effect (Path $a \times b)$ & $0.05(0.01,0.09)$ & 0.021 & 2.30 & \\
\hline
\end{tabular}

Knee MPS --> tested knee pain intensity

\begin{tabular}{|c|c|c|c|c|}
\hline Total Effect & $0.13(0.06,0.20)$ & 0.034 & 3.79 & $-\cdots$ \\
\hline Path $a$ & $0.09(0.02,0.17)$ & 0.037 & 2.44 & $30 \%(4 \%, 57 \%)$ \\
\hline Path $b$ & $0.43(0.23,0.63)$ & 0.103 & 4.19 & \\
\hline Direct Effect (Path $c$ ) & $0.09(0.03,0.15)$ & 0.031 & 2.86 & \\
\hline Indirect Effect (Path $a \times b)$ & $0.04(0.00,0.08)$ & 0.019 & 2.11 & \\
\hline Path $a$ & $0.13(0.04,0.22)$ & 0.045 & 2.79 & $29 \%(3 \%, 56 \%)$ \\
\hline Path $b$ & $0.30(0.13,0.47)$ & 0.088 & 3.41 & \\
\hline Direct Effect (Path $c$ ) & $0.09(0.03,0.16)$ & 0.033 & 2.75 & \\
\hline Indirect Effect (Path $a \times b)$ & $0.04(0.00,0.07)$ & 0.018 & 2.16 & \\
\hline
\end{tabular}

$\beta=\beta$-coefficient; $\mathrm{Cl}=$ confidence interval; * $\mathrm{p}<0.05$ if bold. $\mathrm{SE}=$ standard error; $\mathrm{Z}=\mathrm{Z}$-score; MPS = mechanical pain sensitivity. 
Table 6 Mediation analysis for QST measures and self-reported pain intensity including a latent psychosocial

mediating variable

\begin{tabular}{|c|c|c|c|c|}
\hline & $\beta(95 \% \mathrm{Cl})^{*}$ & SE & $\mathbf{Z}$ & $\begin{array}{c}\text { Proportion of Total } \\
\text { Effect Mediated }(95 \% \mathrm{Cl})\end{array}$ \\
\hline \multicolumn{5}{|l|}{ Global Pain Intensity } \\
\hline \multicolumn{5}{|l|}{ Exogenous: Tender Point } \\
\hline Total Effect & $0.47(0.18,0.75)$ & 0.144 & 3.24 & ---- \\
\hline Indirect Effect (path $a \times b$ ) & $0.35(0.13,0.57)$ & 0.112 & 3.15 & $75 \%(22 \%, 100 \%)$ \\
\hline Direct Effect (path $c$ ) & $0.12(-0.18,0.41)$ & 0.149 & 0.77 & \\
\hline \multicolumn{5}{|l|}{ Exogenous: Knee MPS } \\
\hline Total Effect & $0.12(0.05,0.20)$ & 0.038 & 3.26 & ---- \\
\hline Indirect Effect (path $a \times b$ ) & $0.07(0.02,0.12)$ & 0.026 & 2.54 & $49 \%(12 \%, 86 \%)$ \\
\hline Direct Effect (path $c$ ) & $0.06(-0.01,0.13)$ & 0.035 & 1.69 & \\
\hline \multicolumn{5}{|l|}{ Exogenous: Knee DMA } \\
\hline Total Effect & $0.33(0.03,0.63)$ & 0.153 & 2.17 & ---- \\
\hline Indirect Effect (path $a \times b$ ) & $0.21(0.01,0.41)$ & 0.010 & 2.10 & $63 \%(5 \%, 100 \%)$ \\
\hline Direct Effect (path $c$ ) & $0.12(-0.14,0.38)$ & 0.134 & 0.90 & \\
\hline \multicolumn{5}{|l|}{ Knee Pain intensity } \\
\hline \multicolumn{5}{|l|}{ Exogenous: Knee MPS } \\
\hline Total Effect & $0.13(0.06,0.20)$ & 0.034 & 3.79 & ---- \\
\hline Indirect Effect (path $a \times b$ ) & $0.04(0.00,0.07)$ & 0.020 & 2.09 & $30 \%(2 \%, 58 \%)$ \\
\hline Direct Effect (path $c$ ) & $0.08(0.02,0.15)$ & 0.034 & 2.50 & \\
\hline \multicolumn{5}{|l|}{ Exogenous: Knee DMA } \\
\hline Total Effect & $0.43(0.17,0.70)$ & 0.134 & 3.25 & ---- \\
\hline Indirect Effect (path $a \times b$ ) & $0.13(-0.01,0.27)$ & 0.070 & 1.90 & $31 \%(0 \%, 61 \%)$ \\
\hline Direct Effect (path $c$ ) & $0.30(0.05,0.56)$ & 0.129 & 2.34 & \\
\hline
\end{tabular}

$\beta=\beta$-coefficient $\mathrm{Cl}=$ confidence interval; ${ }^{*} \mathrm{p}<0.05$ if bold. $\mathrm{SE}=$ standard error; $\mathrm{Z}=\mathrm{Z}$-score; MPS = mechanical pain sensitivity; $\mathrm{DMA}=$ dynamic mechanical allodynia. 


\section{Appendix A}

\section{Quantitative sensory testing battery}

Tender point count

An 18 point tender point count was performed following the ACR protocol for classifying Fibromyalgia ${ }^{[23]}$. Subjects were asked to rate whether they felt "pressure", "discomfort", or "pain" when pressure was applied to the 9 sites on the right and left sides of the body (18 in total). Pressure was applied by the assessor using their thumb at a rate of $1 \mathrm{~kg}$ per second up to $4 \mathrm{~kg}$ unless the subject indicated discomfort or pain.

\section{Thermal pain thresholds}

Heat and cold pain thresholds were assessed using the TSA 2001-II Thermode (MEDOC, Israel) at the knee and forearm $\left(0\right.$ to $50^{\circ} \mathrm{C}$; MEDOC, Israel). The thermode was set to a baseline temperature of $32^{\circ}$ and increased (heat pain) or decreased (cold pain) in temperature at a rate of $1^{\circ} \mathrm{C}$ per second until the participant indicated pain or until the safety cut-off points at $50^{\circ} \mathrm{C}$ or $0^{\circ} \mathrm{C}$ were reached. Thresholds were determined by taking the average of three readings for each threshold.

\section{Mechanical pain threshold}

Mechanical pain thresholds were assessed using 7 punctate probes $(8-512$ milli-Newton $(\mathrm{mN})$; MRC Systems $\mathrm{GmBH}$, Germany); the probes were applied in ascending order until a participant reported the probe to feel "sharp". Once a "sharp" response was obtained, the probes were applied in descending order until a "blunt" response was achieved. Mechanical pain threshold was determined by taking the geometric mean of the weight of the probes for 5 "sharp" and 5 "blunt" responses.

\section{Mechanical pain sensitivity}

The 7 punctate probes were also used to assess MPS as well as two cotton buds of differing size and a brush to determine DMA as part of the stimulus response function at the knee and forearm. The 10 stimuli 
were applied in a random order and five times each in total with participants asked to provide a rating of pain scored from 0 (no pain) to 100 (worst pain imaginable) for each stimulus. The 35 scores for the punctate probes were averaged to provide a score for MPS with the mean of the 15 responses to the cotton buds and brush forming the score for DMA.

\section{Temporal summation}

Central measures of QST included wind-up ratio at the knee and forearm. A single application of the $256 \mathrm{mN}$ punctate probe and series of 10 applications of the same probe at a rate of one per second was applied to the knee and forearm; participants were asked to rate the single and series of applications using the 0 to 100 NRS described above. Wind-up ratio was calculated from the mean rating of 5 series of applications divided by the mean rating for 5 single applications of the probe.

\section{Vibration detection threshold}

Vibration detection was assessed using a $64 \mathrm{~Hz}$ Rydel Seiffer tuning fork (US Neurologicals, USA); the tuning fork was placed upon the patella or at the elbow while vibrating with participants asked to report whether they felt vibration, and to indicate when the vibration stopped. A scale of 0 to 8 on the tuning fork was used to identify the point of cessation. Thresholds were calculated by taking the mean of three assessments.

\section{Pressure pain threshold}

Pressure pain thresholds were assessed using a hand-held algometer ( 0 to $10 \mathrm{~kg} / \mathrm{cm}^{2}$; Pain Diagnostics and Thermography, USA) with pressure applied at a rate of $1 \mathrm{~kg}$ per second at the knee and forearm until 10 $\mathrm{kg}$ was reached or the participant indicated pain. Thresholds were calculated as the mean of three assessments. 


\section{Psychosocial factors partially mediate the relationship between}

\section{mechanical hyperalgesia and self-reported pain}

Kayleigh J Mason', Terence W O’Neill1, 2, 3, Mark Lunt ${ }^{1,2}$, Anthony KP Jones ${ }^{3,4}$, John McBeth ${ }^{1,2}$

1. Division of Musculoskeletal and Dermatological Sciences, The University of Manchester, Manchester, UK

2. NIHR Manchester Musculoskeletal Biomedical Research Unit, Manchester Academic Health Science Centre, Manchester, UK

3. Department of Rheumatology, Salford Royal NHS Foundation Trust, Salford, UK

4. Human Pain Research Group, Division of Neuroscience and Experimental Psychology, The University of Manchester, UK

Coresponding author: Kayleigh J. Mason, BADBIR, Rutherford House (Unit 1), Manchester Science Park, 40 Pencroft Way, Manchester, M15 6SZ; email: kayleigh.mason@manchester.ac.uk, Tel.: +44 (0) 161306 1908, Fax: +44 (0) 1613061912 


\begin{abstract}
Background and aim: Amplification of sensory signalling within the nervous system along with psychosocial factors contributes to the variation and severity of knee pain. Quantitative Sensory Testing (QST) is a noninvasive test battery that assesses sensory perception of thermal, pressure, mechanical and vibration stimuli used in the assessment of pain. Psychosocial factors also have an important role in explaining the occurrence of pain. The aim was to determine whether QST measures were associated with self-reported pain, and whether those associations were mediated by psychosocial factors.
\end{abstract}

Methods: Participants with knee pain identified from a population-based cohort completed a tender point count and a reduced QST battery of thermal, mechanical and pressure pain thresholds, temporal summation, mechanical pain sensitivity, dynamic mechanical allodynia and vibration detection threshold performed following the protocol by the German Research Network on Neuropathic Pain. QST assessments were performed at the most painful knee and opposite forearm (if pain-free). Participants were asked to score for their global and knee pain intensities within the past month (range 0 to 10), and complete questionnaire items investigating anxiety, depression, illness perceptions, pain catastrophizing, and physical functioning. QST measures (independent variable) significantly correlated (Spearman's rho) with selfreported pain intensity (dependent variable) were included in structural equation models with psychosocial factors (latent mediators).

Results: 72 participants were recruited with 61 participants (36 women; median age 64 years) with complete data included in subsequent analyses. Tender point count was significantly correlated with global pain intensity. Dynamic mechanical allodynia at the knee and mechanical pain sensitivity at the most painful knee and opposite pain-free forearm were significantly correlated with both global pain and knee pain intensities. Psychosocial factors including pain catastrophising sub-scales (rumination and helplessness) and illness perceptions (consequences and concern) were significant partial mediators of the association with global pain intensity when loaded on to a latent mediator for: tender point count $(75 \%$ total effect; $95 \%$ confidence interval 22\%, 100\%); mechanical pain sensitivity at the knee (49\%; 12\%, 86\%); and dynamic mechanical allodynia at the knee $(63 \% ; 5 \%, 100 \%)$. Latent psychosocial factors were also significant partial mediators of the association between pain intensity at the tested knee with mechanical pain sensitivity at the knee (30\%; $2 \%, 58 \%$ ), but not for dynamic mechanical allodynia at the knee.

Conclusions: Measures of mechanical hyperalgesia at the most painful knee and pain-free opposite forearm were associated with increased knee and global pain indicative of altered central processing. 
Psychosocial factors were significant partial mediators, highlighting the importance of the central integration of emotional processing in pain perception.

Implications: Associations between mechanical hyperalgesia at the forearm and knee, psychosocial factors, and increased levels of clinical global and knee pain intensity provide evidence of altered central processing as a key mechanism in knee pain, with psychological factors playing a key role in the expression of clinical pain.

\section{Key words}

knee pain; quantitative sensory testing; sensitisation; psychosocial factors; altered central processing 


\section{Abbreviations}

$\begin{array}{ll}\text { BMI } & \text { Body Mass Index } \\ \text { CI } & \text { Confidence Interval } \\ \text { DMA } & \text { Dynamic Mechanical Allodynia } \\ \text { EPIFUND } & \text { Epidemiology of Functional Disorders } \\ \text { HAD } & \text { Hospital Anxiety and Depression scale } \\ \text { ICC } & \text { Intraclass Correlation Coefficient } \\ \text { IPQ-brief } & \text { Brief Illness Perception Questionnaire } \\ \text { IQR } & \text { Interquartile Range } \\ \text { MPS } & \text { Mechanical Pain Sensitivity } \\ \text { OA } & \text { Osteoarthritis } \\ \text { PCS } & \text { Pain Catastrophising Scale } \\ \text { QST } & \text { Quantitative Sensory Testing } \\ \text { RAPA } & \text { Rapid Assessment of Physical Activity } \\ \text { SMD } & \text { Standardised Mean Difference }\end{array}$




\section{Introduction}

Knee pain is a common complaint in the ageing population with an annual prevalence of $25 \%$ in those over $55^{[1]}$. Knee pain may arise through local pathology stimulating the release of inflammatory mediators triggering nociceptive transmission ${ }^{[2]}$. Only moderate correlations exist between knee pain and the structural pathology of osteoarthritis (OA) such as bone marrow lesions, synovitis and subchondral bone oedema, suggesting that altered central processing may be responsible for certain components of chronic pain ${ }^{[3,4]}$. In those with chronic pain, altered central processing through amplifications of somatosensory inputs either via hyperalgesia (hypersensitivity to painful stimuli near a painful site) or allodynia (hypersensitivity to nonpainful stimuli near a painful site), and the integration of emotional processing can contribute to the experience of pain in the absence of peripheral damage ${ }^{[5,6]}$; altered central processing is an important mechanism for understanding the discordance between pathological features of $O A$ and knee pain intensity. Higher reported pain knee intensity is associated with increased sensitivity to temporal summation (repeated noxious stimulation lowering the threshold for nociceptive transmission) in patients with knee OA indicating altered central processing ${ }^{[7,8]}$.

Quantitative sensory testing (QST) is a non-invasive technique used to assess somatosensory functioning ${ }^{\left[{ }^{9]}\right.}$. There is preliminary evidence to suggest knee OA patients have diminished vibration detection ${ }^{[10]}$ and thermal pain thresholds ${ }^{[11,12]}$ compared with healthy volunteers; however, previous studies have not investigated whether these measures are associated with higher levels of self-reported knee pain intensity. Two recent systematic reviews investigated somatosensory functioning in OA samples. Lluch et al. ${ }^{[13]}$ reported that despite diverse methodologies, increased levels of local hyperalgesia (at the knee, indicating peripheral sensitisation) and widespread hyperalgesia (indicating central sensitisation) were observed for knee OA participants compared with pain-free controls. A meta-analysis by Fingleton et al. ${ }^{[14]}$ demonstrated pressure pain thresholds were significantly lower in patients with knee OA compared with pain-free controls (standardised mean difference [SMD] -0.85; 95\% confidence interval [Cl] -1.1, -0.6), and for knee OA groups with high symptom severity compared with those with low symptom severity (SMD $-0.51 ; 95 \% \mathrm{Cl}-0.73$, 0.30). The authors also identified temporal summation as present in knee OA patients compared with healthy controls, and for knee OA groups with high symptom severity compared with low symptom severity [14]. These findings suggest altered central processing is present within a sub-sample of individuals with knee OA and chronic pain.

Recent studies investigating QST in knee OA samples have included measures of psychosocial distress. Cruz-Almeida et al. ${ }^{[15]}$ determined four distinct profiles from psychological and somatosensory measures for 
194 individuals with knee OA using hierarchical cluster analysis with the two most severe clusters reporting the highest levels of pain, anger, depression and mechanical hyperalgesia ${ }^{[15]}$. Findings from Williams et al. ${ }^{[12]}$ and Finan et al. ${ }^{[8]}$ demonstrated higher levels of anxiety and depression in participants with lower grade radiographic disease and moderate to severe knee pain, which were associated with higher levels of disability and widespread hyperalgesia. These results indicate psychosocial factors are associated with altered central processing with low grades of underlying pathology. However, the role of illness perceptions, which have been demonstrated as possible targets for intervention in people with lower back pain ${ }^{[16]}$, have not been addressed in people with knee pain.

The impact of psychosocial factors on the association between self-reported pain intensity and somatosensory functioning has yet to be investigated in a population-based sample of individuals with knee pain. The aim of the present study was to determine whether (i) higher levels of self-reported pain intensity were associated with greater sensitivity to QST measures; (ii) any association between QST measures and pain intensity was mediated by psychosocial factors.

\section{Methods}

\subsection{Participants}

565 participants with knee pain were identified from a prospective population-based cohort investigating chronic pain (the epidemiology of functional disorders [EPIFUND] cohort) ${ }^{[17] . ~ P a r t i c i p a n t s ~ w e r e ~ e l i g i b l e ~ f o r ~}$ this study if they responded to a postal survey, had knee pain, and consented to further contact. It was not possible to robustly identify whether participants in the EPIFUND cohort identified as having knee pain also had underlying OA.

\subsection{Recruitment}

A two-phase telephone recruitment strategy was used: eligible participants were first contacted to verify the presence of knee pain on at least one day in the past month and to consent to the mailing of the participant information sheet about the QST study for their consideration. The second phone call occurred at least 7 days following the first-call to ensure adequate time for delivery and consideration of the information sheet. A more detailed description of the study was provided during the second phone call and if they were interested, participants were invited to attend a 90 minute appointment at a local primary care or research centre. A letter containing details of the study appointment, including the time, date and location, was mailed to each 
participant who agreed to take part. The present study received approval from the National Research Ethics Service Committee North West - Cheshire (12/NW/0556) in order to contact the cohort and complete the study assessments. All participants provided consent at the study visit prior to any assessments.

\subsection{Study Assessments}

All assessments during the study visit were performed by one rater (KJM).

\subsection{Self-reported pain intensity and body mass index (BMI)}

All participants were asked whether they had experienced pain that lasted one day or longer in the past 30 days and to indicate that pain on a blank-body manikin. Participants with knee pain were those who shaded one or both knee regions. Global and knee pain intensities were assessed using 0 to 10 (best to worst) numeric rating scales for the average pain severity experienced within the past 30 days. BMI was calculated from measured weight (kilograms) and height (metres²).

\subsection{Psychosocial Factors}

Participants were provided with a questionnaire, including items addressing anxiety, depression, illness perceptions, pain catastrophising and physical functioning, with a stamped and addressed envelope to mail back to the study team after the assessments were complete. The Hospital Anxiety and Depression (HAD) scale ${ }^{[18]}$ comprises 7 anxiety and 7 depression items (items scored 0 , no symptoms to 3 , strong indication of symptoms; anxiety and depression scales score range $0-21 ; 0$ to 7 classified as normal; 8 to 10 as borderline cases; and $\geq 11$ as cases). The Pain Catastrophizing Scale (PCS) and Brief Illness Perception Questionnaire (IPQ-brief) measured cognitions about pain [19]. The PCS comprises 13 items scored 0 (not at all) to 4 (all of the time) forming three sub-scales: helplessness (6 items, range $0-24$ ), rumination (4 items, range 0-16) and magnification (3 items, range 0-12). The IPQ-brief comprises 8 items scored using a 10point numeric rating scale ${ }^{200]}$; five items (consequences, timeline, personal control, treatment control and identity) address thoughts about the illness, two items (concern and emotion) address the emotional impact and the final item (coherence) relates to the understanding of the illness (pain in the present study). Physical functioning was addressed using the Rapid Assessment of Physical Activity (RAPA) scale. The RAPA includes 9 items (range $0-10$ ) scored "yes" or "no" with 7 items for levels of physical activity ( 0 classified as 
sedentary; 1 to 2 as underactive, 3 to 4 regular underactive, and $\geq 5$ as regular active ( $>5)$, one item for strength (scored 0 or 1 ) and one item for flexibility (scored 0 or 2) [21].

\subsection{Quantitative Sensory Testing}

The QST assessments were performed following the protocol by the German Research Network on Neuropathic Pain [22]. A reduced QST protocol was used; there is limited evidence for the presence of abnormal mechanical or thermal detection thresholds, or paradoxical heat sensations, in knee OA patients. All other assessments were included as these are considered to be altered in those with knee pain (pressure pain; temporal summation) or the literature is conflicting (thermal and mechanical pain, and vibration detection thresholds). QST assessments, except for vibration detection, were performed at the tibial tuberosity of the most painful knee and two centimetres distal to the lateral epicondyle on the opposite forearm (if pain-free): vibration detection was performed on the nearest bony prominences to the test sites in accordance with the QST protocol (at the patella of the most painful knee and the opposite elbow). Participants who did not achieve a painful sensation during cold or heat pain thresholds were categorised as $0^{\circ} \mathrm{C}$ and $50^{\circ} \mathrm{C}$, respectively.

The tender point count was included as a measure of widespread sensitivity to determine whether increased sensitivity to sensory stimuli was localised to the knee or if there was an indication of more generalised changes in pain sensitivity ${ }^{[23]}$. Participants were provided with standardised descriptions of the QST measures and ratings required; a summary of the test battery is provided in Appendix $A$.

\subsection{Sample Size}

In the EPIFUND study [25], the standard deviation of tender point count was 4.5 and of global pain intensity was 2.25, and the regression of global pain intensity on tender point count gave a regression coefficient of 0.16. Entering these values in the G*Power 3.1.2 software suggest that a sample size of 71 participants would be sufficient to give $80 \%$ power to detect this association at a significance level of 0.05 .

\subsection{Analysis}

The characteristics of study participants, QST measures and psychosocial factors are presented as medians with the interquartile range (IQR) for continuous measures and proportions for categorical variables. 
Spearman's correlation was used to determine associations between QST measures and psychosocial factors, and QST measures with both self-reported pain intensities. The QST measures (independent variables) with significant correlations $(\mathrm{p}<0.05)$ with one or both measures of self-reported pain intensity (dependent variables) were selected for the mediation model (path c, Figure 1). Psychosocial factors which were significantly correlated $(p<0.05)$ with the QST measures selected as independent variables were selected as mediating variables for the mediation model (path a, Figure 1). Structural equation models with all psychosocial factors associated with each QST measure loading on to a latent mediator were also constructed (Figure 2). Only participants with complete observations for all measures of interest were included in the analyses. All analyses were performed using Stata 13.1 software (Stata, USA).

\section{<Figure 1; Figure 2>}

\section{Results}

\subsection{Participants}

565 of 1530 responders (37\%; median age 60 years; $62 \%$ female) of the EPIFUND cohort reported knee pain; $213(38 \%)$ of those identified with knee pain were contacted during the first telephone recruitment phase (Figure 3). 133 people (24\%) received a study information sheet and 80 people (14\%) either could not be contacted, reported no knee pain within the past month, or declined participation. 92 people (16\%) agreed to participate in the study. However, 11 people (2\%) did not attend study appointments and 8 people (1\%) were withdrawn during the study visit. 72 participants (13\%) completed the study. 61 participants (11\%; median age 64 years; 59\% women; Table 1) had complete data for QST measures, psychosocial factors, and self-reported pain intensities, and were included in the analyses. The proportion of female EPIFUND responders with knee pain was comparable to the proportion in this study (62\% and 59\%, respectively), although participants in this study were older than the EPIFUND responders (median age 64 years and 60 years, respectively).

\section{<Figure 3>}

\subsection{Participant characteristics}

The median BMI of the 61 participants was 27.7 (IQR 26 to 30.7; Table 1). The medians for self-reported global pain intensity and pain intensity at the tested knee were 5 (IQR 3-7 for both pain intensities). The 
median for tender point count was 0 (IQR 0 to 2) with no participants meeting the 11 tender point threshold outlined in the 1990 ACR Fibromyalgia criteria ${ }^{[23]}$. The median ratios for temporal summation at the knee and forearm exceeded 1 ( 2 and 1.9, respectively) indicating greater pain was reported in response to the train of mechanical stimuli compared with the single stimulus. Apart from the median scores for DMA (which were identical at both test sites), the median thresholds for cold pain, MPS and vibration detection were higher at the forearm than the knee. The median thresholds for heat and pressure pain were lower at the forearm than the knee.

The median scores for the HAD anxiety (3; IQR 1 to 6$)$ and depression (5; IQR 2 to 8 ) sub-scales were below the score for borderline cases (0-7 normal; 8-10 borderline case; 11-21 case). In the present study, 12 borderline and 7 cases of anxiety, and 8 borderline and 3 cases of depression were identified using the HAD sub-scale cut-offs (Table 2) [18]. Median scores of 3 (IQR 1 to 2), 1 (IQR 1 to 3 ) and 3 (IQR 2 to 5 ) were reported for the rumination, magnification and helplessness sub-scales of the PCS, respectively. The median scores for items of the IPQ-Brief were: consequences (3; IQR 2 to 5); timeline (8; IQR 4 to 10; inversely scored); personal control (5; IQR 3 to 7; inversely scored); treatment control (5; IQR 2 to 7; inversely scored); identity (2; IQR 1 to 4); concern (4; IQR 2 to 7); coherence (2; IQR 1 to 5); emotion (3; IQR 1 to 4). A median score of 4 (regular underactive; IQR 4 to 5) was observed for the RAPA.

\section{$<$ Table 1; Table 2>}

\subsection{Correlations between QST measures and self-reported pain intensity}

There were significant positive correlations $(p<0.05$; Table 3 ) between global pain intensity and number of tender points, knee and forearm MPS, and DMA at the knee. Knee and forearm MPS, and DMA at the knee were also significantly positively correlated with higher pain intensity at the tested knee.

\section{$<$ Table 3>}

\section{4. $\quad$ Correlations between QST measures and psychosocial factors}

In total, 10 psychosocial factors were significantly correlated $(p<0.05$; Table 4$)$ with tender point count; seven factors were significantly correlated with knee MPS; nine factors were significantly correlated with DMA at the knee; and 5 factors were significantly correlated with MPS at the forearm. Impact of illness on life, increased illness duration and higher levels of concern (illness perceptions) and magnification (pain 
catastrophizing) were all significantly positively correlated with tender point count, mechanical pain sensitivity at the knee and forearm, and dynamic mechanical allodynia at the knee.

\section{$<$ Table 4>}

\subsection{Mediation Analysis}

Nine significant partial mediators of the associations between QST measures and the self-reported global and knee pain intensity measures were identified (Table 5). The total effect of tender point count on global pain intensity was 0.467 ( $\beta$-coefficient; $95 \% \mathrm{Cl} 0.184,0.749$; Table 5$)$. Within the mediation model, the direct effect (path c; Figure 1) between tender point count and global pain intensity was non-significant ( $\beta$ 0.467; $95 \% \mathrm{Cl}-0.086,0.462$ ). The indirect effect (path a x path b; Figure $1 ; \beta 0.279 ; 95 \% \mathrm{Cl} 0.093,0.465$ ) between tender point count and concern item of the IPQ-brief (path a), and between concern and global pain intensity (path b) was significant. The proportion of the total mediated effect was determined by dividing the $\beta$ coefficient for the indirect effect by the $\beta$-coefficient for the total effect $(0.279 / 0.467=60 \%)$.

The association between increased number of tender points and increased global pain intensity was also significantly partially mediated by the consequences item of the IPQ-brief, and the helplessness and rumination sub-scales of the PCS explaining $57 \%, 56 \%$ and $34 \%$ of the total effect, respectively. Increased knee MPS and increased global pain intensity was partially mediated by concern, consequences and helplessness explaining $45 \%, 40 \%$ and $40 \%$ of the total effect respectively, and increased knee MPS and increased pain intensity at the tested knee were partially mediated by consequences and concern, explaining $30 \%$ and $29 \%$ of the total effect respectively.

\section{$<$ Table 5>}

The inclusion of psychosocial factors loaded on to a latent mediator rather than individual items (Figure 2) accounted for $75 \%, 52 \%, 63 \%$ and $35 \%$ of the total effect of tender point, knee MPS and knee DMA on global pain intensity, and knee MPS on knee pain intensity, respectively (Table 6). However, the latent psychosocial mediator was not a partial mediator of the association between knee DMA on knee pain intensity (30\% total effect mediated; Table 6$)$.

\section{$<$ Table 6>}

\section{Discussion}


The present study identified significant associations between greater levels of self-reported pain intensity

(globally and at the knee) with measures of mechanical hyperalgesia (greater number of tender points, and increased MPS and DMA). The identification of widespread mechanical hyperalgesia (global pain intensity significantly associated with tender point count and forearm MPS) suggests that generalised alterations in central pain processing (an aspect of central sensitisation) contributes to mechanisms of knee pain. The associations between self-reported pain intensity and mechanical hyperalgesia were also explained in part by psychosocial factors, namely illness perceptions, suggests central integration of these phenomena and altered somatosensory processing in those with knee pain.

The present study demonstrated mechanical hyperalgesia (tender points, mechanical pain sensitivity and dynamic mechanical allodynia) at the knee and forearm were associated with greater levels of self-reported pain intensity, but that pain thresholds (heat, cold, mechanical and pressure) and temporal summation at the same sites were not. Previous studies have identified associations between the presence of temporal summation in knee OA samples compared with healthy controls, and between knee OA groups with high symptom severity compared with low symptom severity ${ }^{[7,26]}$. Within-person associations between increased pain severity and measures of pressure pain and temporal summation have been identified in one study [27]; however, the sample size was much larger $(n=2126)$ and the temporal summation methodology applied for a longer time period (30 seconds), which may account for the lack of association in in the present study.

While previous studies have shown somatosensory disturbances in samples with knee pain compared to pain-free controls, a recent population-based study of individuals with knee OA classified according to the median number of disease-related symptoms and a group of pain-free controls demonstrated no differences across the groups for the warm detection, heat pain, or heat pain tolerance thresholds at the knee or forearm, or for cold pain and cold pain tolerance thresholds at the right hand suggesting that peripheral somatosensory disturbances were not present in the knee OA groups ${ }^{[26]}$. However, significantly higher levels of pain intensity were reported for all QST assessments and at all test sites for the high and (to a lesser extent) low symptom count knee OA groups compared with controls ${ }^{[26]}$. These findings suggest the presence of amplification of somatosensory inputs within the central nervous system in those with knee pain. A study by Neogi et al. posits that sensitisation is a trait already present with patients with knee OA and is not a consequence of joint pathology [27]: the authors did not observe associations between the duration, presence or severity of radiographic knee OA with increased sensitivity to pressure pain and mechanical temporal summation suggesting the presence of central sensitisation in their sample. The present study supports this finding as mechanical hyperalgesia at the forearm, a pain-free site opposite to the most painful 
knee, and a greater number of tender points were significantly associated with higher levels of global pain intensity suggesting the presence of altered central processing.

Only one previous study reported pain catastrophizing as a significant partial mediator of the association between female sex and higher levels of self-reported pain intensity, disability and pain behaviour modelled as a latent pain-related outcome measure in 168 subjects with knee OA; these findings indicate women are more likely to report pain, and catastrophizing explains a proportion of that association ${ }^{[28]}$. However, the study did not perform QST assessments [28]. The present study identified measures of catastrophizing along with illness perceptions as partial mediators of the association between QST measures and self-reported pain intensity demonstrating the role of central emotional processing in mediating increasing central pain processing.

Previous studies have demonstrated differences in sensory perception thresholds between participants with

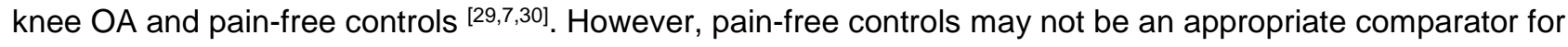
people with chronic pain. Psychosocial factors such as depression, anxiety, pain catastrophizing and lowered physical functioning that influence pain perception occur less frequently in pain-free controls. Other studies have stratified knee OA patients by disease [12], symptom [26], or pain severity [8,7], or have used

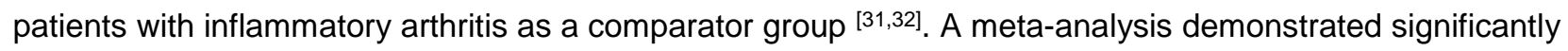
lower pressure pain thresholds in those with knee OA compared with pain-free controls and for knee OA groups with high symptom severity compared with those with low symptom severity ${ }^{[14]}$. The present study used a pain-free test site on the opposite side of the body to the most painful knee to eliminate person-level confounding as all control assessments were performed within-person; consequently, within-person mechanical hyperalgesia along with measures of pain catastrophising and illness perceptions were identified as indicators of greater self-reported pain intensity, suggesting that altered central pain processing contributes to mechanisms of knee pain.

A limitation of the present study is the cross-sectional study design. While insights into the associations between QST measures, pain and psychosocial factors have been provided, it is unknown whether mechanical hyperalgesia or illness perceptions are causal or a consequence of having pain. Another limitation is that the present study was underpowered to fully explore the role of age and sex as moderators of the associations between QST measures and self-reported pain intensity; Bartley et al. ${ }^{[3]}$ demonstrated increased sensitivity to QST measures (cold pressor; mechanical pain; pressure pain) in 183 females compared with 105 males with symptomatic knee OA, despite similar mean values recorded for the WOMAC (34.5 \pm 20.5 for females; $34.1 \pm 20.7$ for males). The authors did observe significantly wider distributions of pain 
sites in females $(6.0 \pm 4.7$ vs $4.3 \pm 3.2)$, which may suggest altered central processing contributing to increased sensitivity in females ${ }^{[3]}$.

A further limitation is the numeric rating scale used to determine global and knee pain intensity levels in the past month in participants; pain intensity in the past month was not associated with current somatosensory thresholds. Previous studies have demonstrated significant associations between pain thresholds and pain in the previous 24 hours ${ }^{[7,34]}$ and current pain ${ }^{[26,35]}$. The inclusion of multiple measures of current and recent knee and/or global pain intensities in future studies exploring current somatosensory functioning should be considered.

\section{Conclusions}

The present study emphasises the contributions of altered central processing and integration of psychosocial factors in the experience of knee pain. Few existing treatments are effective in reducing pain intensity in those with chronic pain in the long term [36]; improving our understanding of the mechanisms driving chronic pain provides new or alternative targets for intervention. The findings of the present study may help to explain inter-individual differences in pain reporting and underscores the role of psychosocial factors in pain research, particularly when investigating variations in the effectiveness of interventions for chronic pain.

\section{Implications}

Associations between mechanical hyperalgesia at the forearm and knee, psychosocial factors, and increased levels of clinical global and knee pain intensity provide evidence of altered central processing as a key mechanism in knee pain with psychological factors playing a key role in the expression of self-reported pain.

\section{Acknowledgements}

The authors express their gratitude to all study participants, Bollington Health and Leisure and NIHR Wellcome Trust Manchester Clinical Research Facility, and to members of the Pain Across the Adult Lifespan study team (James Anderson; Claire Bennett; Dr Deborah Brown; Rosie Duncan; Dr Matthew Mulvey; Dr Amir Rashid). 
Research Funding: Arthritis Research UK programme grant 17552. This report includes independent research supported by (or funded by) the National Institute for Health Research Biomedical Research Unit Funding Scheme. The views expressed in this publication are those of the author(s) and not necessarily those of the NHS, the National Institute for Health Research or the Department of Health.

Conflict of interest: KJM received honoraria for developing and delivering an educational presentation for Janssen-Cilag Ltd and Eli Lilly Ltd. AKPJ is National PI on a drug trial supported by Daichi-Sankyo. The other authors (ML; TON; JM) have no conflicts of interest, including relevant financial interests, activities, relationships, and affiliations.

Informed Consent: All participants provided consent at the study visit prior to any assessments. Participants were anonymised to maintain their privacy.

Ethical approval: The present study received approval from the National Research Ethics Service Committee North West - Cheshire (12/NW/0556) in order to contact the cohort and complete the study assessments. 


\section{References}

[1] Peat G, McCarney R, Croft P. Knee pain and osteoarthritis in older adults: a review of community burden and current use of primary health care. Annals of the Rheumatic Diseases 2001; 60:91-97

[2] Liu-Bryan R, Terkeltaub R. Emerging regulators of the inflammatory process in osteoarthritis. Nat Rev Rheumatol 2015; 11:35-44

[3] Brown CA, El-Deredy W, Jones AK. When the brain expects pain: common neural responses to pain anticipation are related to clinical pain and distress in fibromyalgia and osteoarthritis. European Journal of Neuroscience 2014; 39:663-672

[4] Barr AJ, Campbell TM, Hopkinson D, Kingsbury SR, Bowes MA, Conaghan PG. A systematic review of the relationship between subchondral bone features, pain and structural pathology in peripheral joint osteoarthritis. Arthritis Res Ther 2015; 17:228

[5] Kidd BL, Photiou A, Inglis JJ. The role of inflammatory mediators on nociception and pain in arthritis. Novartis Found Symp 2004; 260:122-133

[6] Woolf CJ. Central sensitization: Implications for the diagnosis and treatment of pain. Pain 2010

[7] Arendt-Nielsen L, Nie H, Laursen MB, Laursen BS, Madeleine P, Simonsen OH, Graven-Nielsen T. Sensitization in patients with painful knee osteoarthritis. Pain 2010; 149:573-581

[8] Finan PH, Buenaver LF, Bounds SC, Hussain S, Park RJ, Haque UJ, Campbell CM, Haythornthwaite JA, Edwards RR, Smith MT. Discordance between pain and radiographic severity in knee osteoarthritis: findings from quantitative sensory testing of central sensitization. Arthritis and Rheumatism 2013; 65:363-372

[9] Shy ME, Frohman EM, So YT, Arezzo JC, Cornblath DR, Giuliani MJ, Kincaid JC, Ochoa JL, Parry GJ, Weimer LH. Quantitative sensory testing. Neurology 2003; 60:898-904

[10] Shakoor N, Agrawal A, Block JA. Reduced lower extremity vibratory perception in osteoarthritis of the knee. Arthritis Care \& Research 2008; 59:117-121

[11] Martinez V, Fletcher D, Bouhassira D, Sessler DI, Chauvin M. The Evolution of Primary Hyperalgesia in Orthopedic Surgery: Quantitative Sensory Testing and Clinical Evaluation Before and After Total Knee Arthroplasty. Anesthesia \& Analgesia 2007; 105:815-821

[12] Williams DA, Farrell MJ, Cunningham J, Gracely RH, Ambrose K, Cupps T, Mohan N, Clauw DJ. Knee pain and radiographic osteoarthritis interact in the prediction of levels of self-reported disability. Arthritis and Rheumatism 2004; 51:558-561

[13] Lluch E, Torres R, Nijs J, Van OJ. Evidence for central sensitization in patients with osteoarthritis pain: a systematic literature review. Eur J Pain 2014; 18:1367-1375

[14] Fingleton C, Smart K, Moloney N, Fullen BM, Doody C. Pain sensitization in people with knee osteoarthritis: a systematic review and meta-analysis. Osteoarthritis Cartilage 2015; 23:1043-1056

[15] Cruz-Almeida Y, King CD, Goodin BR, Sibille KT, Glover TL, Riley JL, Sotolongo A, Herbert MS, Schmidt J, Fessler BJ, Redden DT, Staud R, Bradley LA, Fillingim RB. Psychological profiles and pain characteristics of older adults with knee osteoarthritis. Arthritis Care Res (Hoboken ) 2013; 65:1786-1794 
[16] Glattacker M, Heyduck K, Meffert C. Illness beliefs, treatment beliefs and information needs as starting points for patient information--evaluation of an intervention for patients with chronic back pain. Patient Education and Counseling 2012; 86:378-389

[17] Chiu YH, Silman AJ, Macfarlane GJ, Ray D, Gupta A, Dickens C, Morriss R, McBeth J. Poor sleep and depression are independently associated with a reduced pain threshold. Results of a population based study. Pain 2005; 115:316-321

[18] Zigmond AS, Snaith RP. The hospital anxiety and depression scale. Acta Psychiatrica Scandinavica 1983; 67:361-370

[19] Sullivan MJL, Bishop SR, Pivik J. The pain catastrophizing scale: Development and validation. Psychological assessment 1995; 7:524

[20] Broadbent E, Petrie KJ, Main J, Weinman J. The brief illness perception questionnaire. Journal of Psychosomatic Research 2006; 60:631-637

[21] Topolski TD, LoGerfo J, Patrick DL, Williams B, Walwick J, Patrick MB. The Rapid Assessment of Physical Activity (RAPA) among older adults. Preventing chronic disease 2006; 3:A118

[22] Rolke R, Magerl W, Campbell KA, Schalber C, Caspari S, Birklein F, Treede RD. Quantitative sensory testing: a comprehensive protocol for clinical trials. Eur J Pain 2006; 10:77-88

[23] Wolfe F, Smythe HA, Yunus MB, Bennett RM, Bombardier C, Goldenberg DL, Tugwell P, Campbell SM, Abeles M, Clark P, . The American College of Rheumatology 1990 Criteria for the Classification of Fibromyalgia. Report of the Multicenter Criteria Committee. Arthritis and Rheumatism 1990; 33:160-172

[24] Wylde V, Palmer S, Learmonth ID, Dieppe P. Test-retest reliability of Quantitative Sensory Testing in knee osteoarthritis and healthy participants. Osteoarthritis and Cartilage 2011; 19:655-658

[25] Brown D, Mulvey M, Cordingley L, Rashid A, Horan M, Pendleton N, Duncan R, McBeth J. The relationship between psychological distress and multiple tender points across the adult lifespan. Arch Gerontol Geriatr 2016; 63:102-107

[26] King CD, Sibille KT, Goodin BR, Cruz-Almeida Y, Glover TL, Bartley E, Riley JL, Herbert MS, Sotolongo A, Schmidt J, Fessler BJ, Redden DT, Staud R, Bradley LA, Fillingim RB. Experimental pain sensitivity differs as a function of clinical pain severity in symptomatic knee osteoarthritis. Osteoarthritis Cartilage 2013; 21:1243-1252

[27] Neogi T, Frey-Law L, Scholz J, Niu J, Arendt-Nielsen L, Woolf C, Nevitt M, Bradley L, Felson DT, for the Multicenter Osteoarthritis (MOST) Study. Sensitivity and sensitisation in relation to pain severity in knee osteoarthritis: trait or state? Annals of the Rheumatic Diseases 2013; DOI: 10.1136/annrheumdis-2013-204191:

[28] Keefe FJ, Lefebvre JC, Egert JR, Affleck G, Sullivan MJ, Caldwell DS. The relationship of gender to pain, pain behavior, and disability in osteoarthritis patients: the role of catastrophizing. Pain 2000; 87:325-334

[29] Imamura M, Imamura ST, Kaziyama HH, Targino RA, Hsing WT, de Souza LP, Cutait MM, Fregni F, Camanho GL. Impact of nervous system hyperalgesia on pain, disability, and quality of life in patients with knee osteoarthritis: a controlled analysis. Arthritis and Rheumatism 2008; 59:14241431 
[30] Wylde V, Palmer S, Learmonth ID, Dieppe P. Somatosensory abnormalities in knee OA. Rheumatology 2012; 51:535-543

[31] Gerecz-Simon EM, Tunks ER, Heale JA, Kean WF, Buchanan WW. Measurement of pain threshold in patients with rheumatoid arthritis, osteoarthritis, ankylosing spondylitis, and healthy controls. Clinical Rheumatology 1989; 8:467-474

[32] Hendiani JA, Westlund KN, Lawand N, Goel N, Lisse J, McNearney T. Mechanical sensation and pain thresholds in patients with chronic arthropathies. The Journal of Pain 2003; 4:203-211

[33] Bartley EJ, King CD, Sibille KT, Cruz-Almeida Y, Riley JL, III, Glover TL, Goodin BR, Sotolongo AS, Herbert MS, Bulls HW, Staud R, Fessler BJ, Redden DT, Bradley LA, Fillingim RB. Enhanced Pain Sensitivity Among Individuals With Symptomatic Knee Osteoarthritis: Potential Sex Differences in Central Sensitization. Arthritis Care Res (Hoboken ) 2016; 68:472-480

[34] Skou ST, Graven-Nielsen T, Lengsoe L, Simonsen O, Laursen MB, Arendt-Nielsen L. Relating clinical measures of pain with experimentally assessed pain mechanisms in patients with knee osteoarthritis. Scandinavian Journal of Pain 2013; 4:111-117

[35] Skou ST, Graven-Nielsen T, Rasmussen S, Simonsen OH, Laursen MB, Arendt-Nielsen L. Widespread sensitization in patients with chronic pain after revision total knee arthroplasty. Pain 2013; 154:1588-1594

[36] Eccleston C, Morley SJ, Williams AC. Psychological approaches to chronic pain management: evidence and challenges. British Journal of Anaesthesia 2013; 111:59-63 
Figure 1 Mediation model

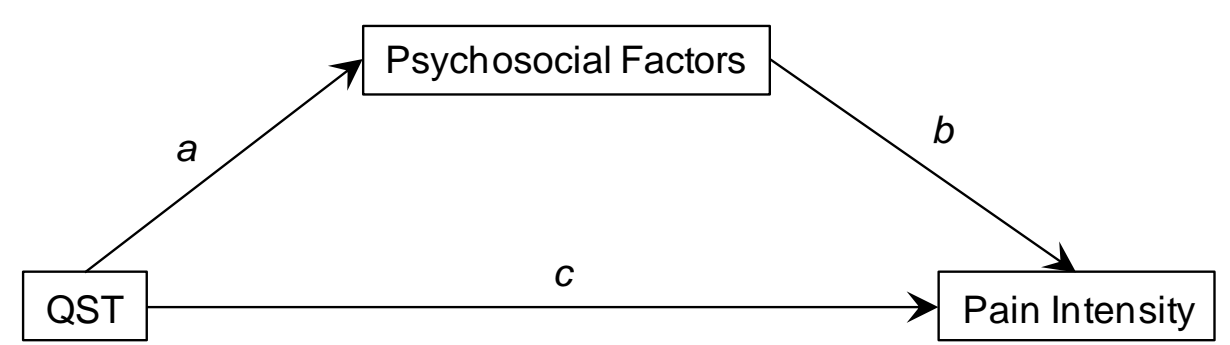

The direct effect is represented by path $\mathrm{c}$ between the independent and dependent variables. The indirect path is represented by path a between the independent and mediator variables, and path $b$ between the mediator and dependent variables. 
Figure 2 Mediation model including latent psychosocial mediating variable

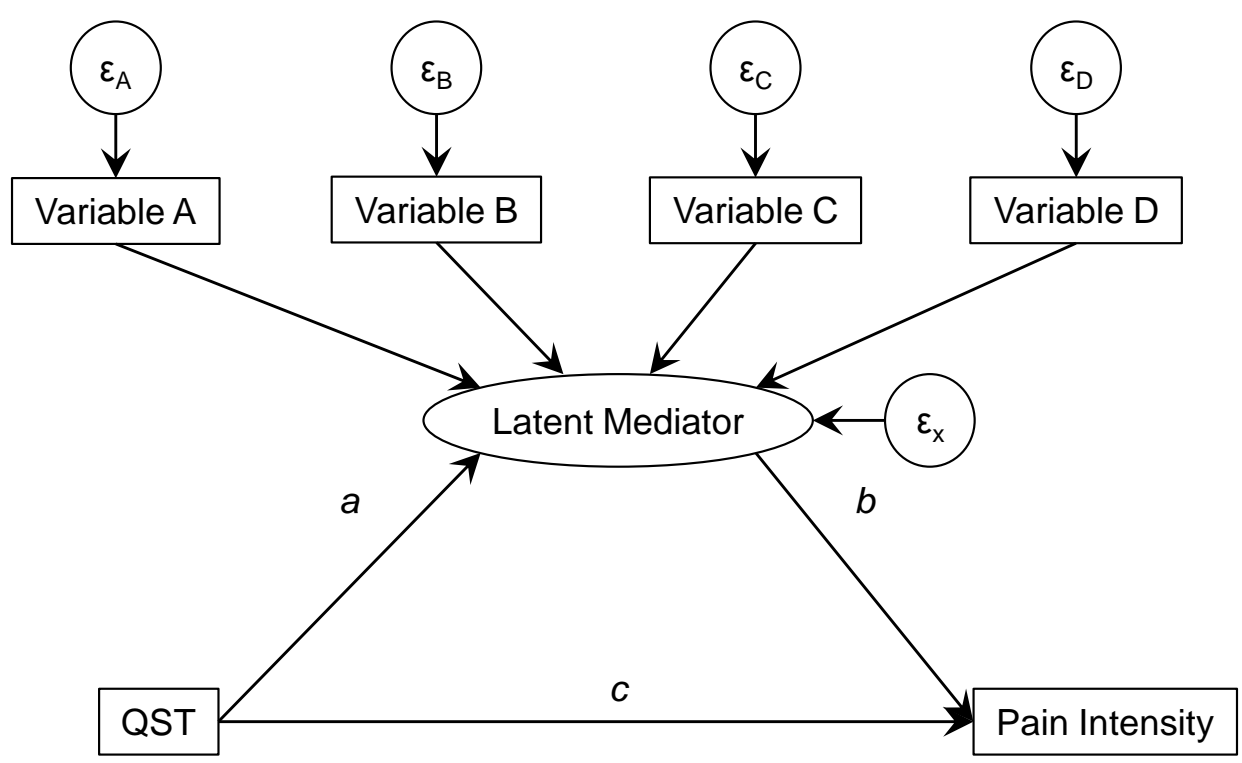

Path c represents the direct effect between the independent and dependent variables. Paths $a$ and $b$ represent the indirect path between the independent and mediator variables (path a), and between the mediator and dependent variables (path b).

$\varepsilon=$ error term; QST = quantitative sensory testing. 
Figure 3 Recruitment flowchart

1
565 identified with knee pain

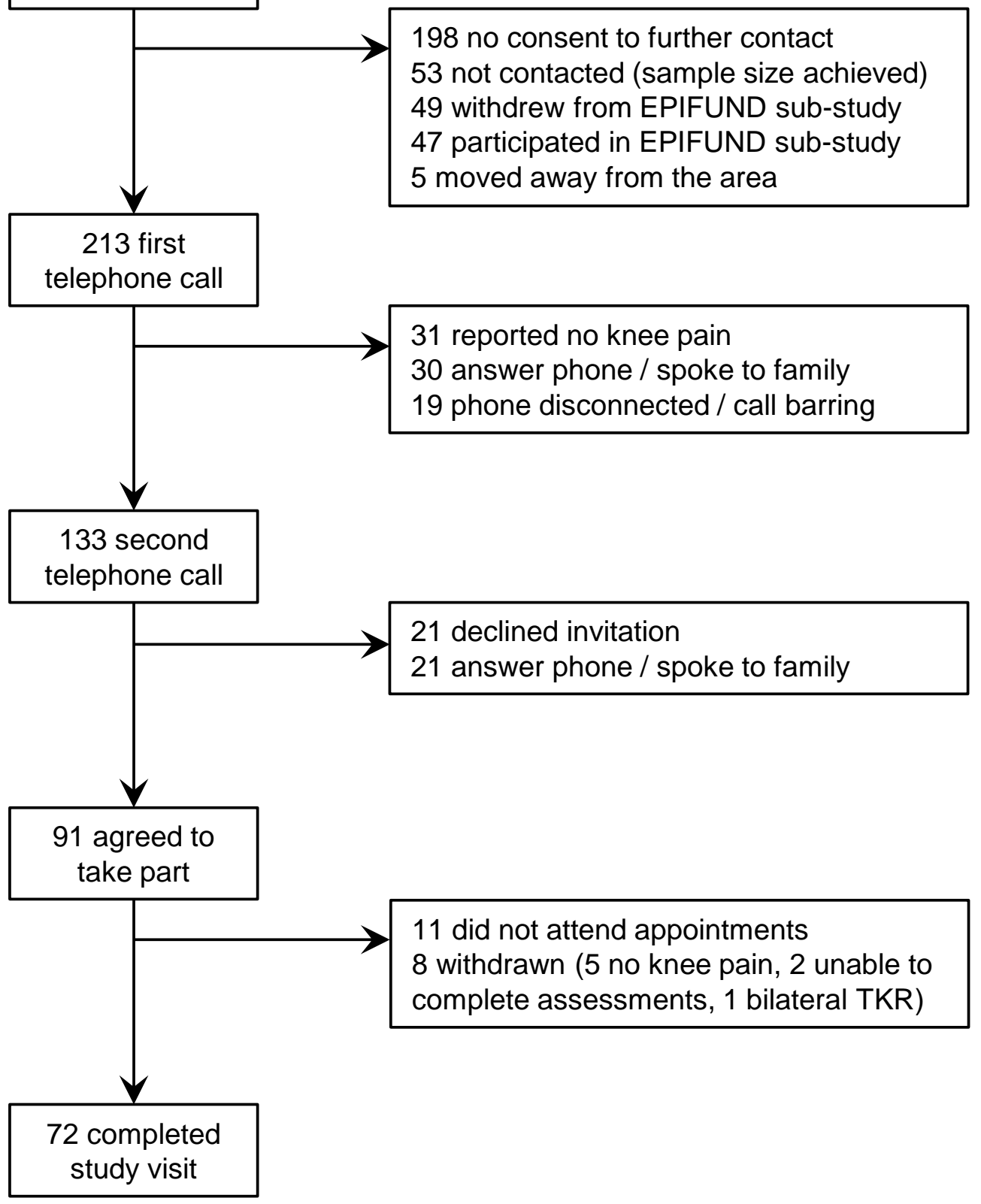


Table 1 Participant characteristics: self-reported pain and QST measures

\begin{tabular}{|c|c|}
\hline Variable (observed range) & $\mathrm{N}=61$ \\
\hline Females (\%) & $36(59.0 \%)$ \\
\hline Age (years; median (IQR)) & 64 (56 to 69$)$ \\
\hline BMI (kg/m2; median (IQR)) & 27.7 (26 to 30.7 ) \\
\hline \multicolumn{2}{|l|}{ Outcome Measures } \\
\hline Global pain intensity (0 to $10 \mathrm{NRS}$ ) & 5 (3 to 7$)$ \\
\hline Tested knee pain intensity (0 to $10 \mathrm{NRS}$ ) & 5 (3 to 7$)$ \\
\hline \multicolumn{2}{|l|}{ Central QST } \\
\hline Tender point ( 0 to 18 ) & $0(0$ to 2$)$ \\
\hline Knee temporal summation $(\geq 1)$ & $1(0.8$ to 1.48$)$ \\
\hline Forearm temporal summation $(\geq 1)$ & $2(1.42$ to 2.67$)$ \\
\hline \multicolumn{2}{|l|}{ Knee QST } \\
\hline Cold pain $\left(0\right.$ to $\left.32.0^{\circ} \mathrm{C}\right)$ & $0(0$ to 0.8$)$ \\
\hline Heat pain $\left(32.0\right.$ to $\left.50^{\circ} \mathrm{C}\right)$ & 48.33 (45.3 to 50$)$ \\
\hline Mechanical pain ( 0 to $512 \mathrm{mN}$ ) & 90.51 (42.22 to 174.18$)$ \\
\hline MPS (0 to 100 NRS) & 2.49 (0.86 to 5.97$)$ \\
\hline DMA (0 to $100 \mathrm{NRS}$ ) & $0(0$ to 1$)$ \\
\hline Vibration (0 to 8 ) & 4.33 (3.33 to 5.33$)$ \\
\hline Pressure pain $(0$ to $10 \mathrm{~kg} / \mathrm{cm} 2)$ & $5.6(3.4$ to 7.3$)$ \\
\hline \multicolumn{2}{|l|}{ Forearm QST } \\
\hline Cold pain $\left(0\right.$ to $\left.32.0^{\circ} \mathrm{C}\right)$ & $1.3(0$ to 14.3$)$ \\
\hline Heat pain $\left(32.0\right.$ to $\left.50^{\circ} \mathrm{C}\right)$ & 47.03 (45.1 to 48.57$)$ \\
\hline Mechanical pain (0 to $512 \mathrm{mN}$ ) & 45.25 (21.11 to 105$)$ \\
\hline MPS (0 to 100 NRS) & 2.97 (0.94 to 7.17$)$ \\
\hline DMA (0 to 100 NRS) & $0(0$ to 0.2$)$ \\
\hline Vibration (0 to 8 ) & 6 (5.33 to 6.67$)$ \\
\hline Pressure pain (0 to $10 \mathrm{~kg} / \mathrm{cm} 2)$ & 3.67 (2.57 to 5.13$)$ \\
\hline
\end{tabular}

$\mathrm{IQR}=$ interquartile range; NRS = numeric rating scale; $\mathrm{CPT}=$ cold pain threshold; HPT = heat pain threshold; $\mathrm{MPT}=$ mechanical pain threshold; $\mathrm{mN}$ = milli-Newton; MPS = mechanical pain sensitivity; DMA = dynamic mechanical allodynia; VDT = vibration detection threshold; PPT = pressure pain threshold. 
Table 2 Participant characteristics: psychosocial factors

\begin{tabular}{|c|c|}
\hline Variable (observed range) & Median (IQR) \\
\hline \multicolumn{2}{|l|}{ HAD (0 to 21 sub-scale) } \\
\hline Anxiety & 5 (2 to 8$)$ \\
\hline Depression & 3 (1 to 6$)$ \\
\hline \multicolumn{2}{|l|}{ PCS } \\
\hline Rumination (4 items; 0 to 16 ) & $3(1$ to 5$)$ \\
\hline Magnification (3 items; 0 to 12 ) & 1 (1 to 3$)$ \\
\hline Helplessness (6 items; 0 to 24 ) & $3(2$ to 5$)$ \\
\hline \multicolumn{2}{|l|}{ IPQ-brief (0 to 10 NRS per item) } \\
\hline Consequences & $3(2$ to 5$)$ \\
\hline Timeline & $8(4$ to 10$)$ \\
\hline Personal Control & 5 (3 to 7$)$ \\
\hline Treatment Control & 5 (2 to 7$)$ \\
\hline Identity & $2(1$ to 4$)$ \\
\hline Concern & $4(2$ to 7$)$ \\
\hline Coherence & $2(1$ to 5$)$ \\
\hline Emotion & $3(1$ to 4$)$ \\
\hline \multicolumn{2}{|l|}{ Physical Functioning } \\
\hline RAPA (7 items; 0 to 7 ) & $4(4$ to 5$)$ \\
\hline
\end{tabular}

$\mathrm{HAD}=$ Hospital Anxiety and Depression Scale; PCS = Pain Catastrophizing Scale; IPQ-brief = IIIness Perception Questionnaire Brief; RAPA $=$ Rapid Assessment of Physical Activity. 
Table 3 Association between self-reported pain intensity and QST measures

1

2

3

4

5

6

7

8

9

10

11

12

13

14

15

16

17

18

19

20

21

22

23

24

25

26

27

28

29

30

31

32

33

34

35

36

37

38

39

40

41

42

43

44

45

46

47

48

49

50

51

52

53

54

55

56

57

58

59

60

61

62

63

64

65

\begin{tabular}{rcc} 
& \multicolumn{2}{c}{ Pain Intensity (NRS) } \\
\cline { 2 - 3 } & Global & Tested knee \\
\hline Central QST & & \\
\hline Tender point & $\mathbf{0 . 3 3 6 4}$ & 0.1811 \\
Knee TS & -0.0608 & -0.1034 \\
Forearm TS & 0.0970 & 0.1433 \\
\hline Knee QST & & \\
\hline CPT & 0.1948 & 0.2430 \\
HPT & -0.0731 & 0.0153 \\
MPT & 0.0844 & 0.1146 \\
MPS & $\mathbf{0 . 3 3 6 6}$ & $\mathbf{0 . 3 3 5 0}$ \\
DMA & $\mathbf{0 . 3 3 3 6}$ & $\mathbf{0 . 4 3 5 8}$ \\
VDT & 0.0169 & -0.0929 \\
PPT & -0.2211 & -0.1443 \\
\hline Forearm QST & & \\
\hline CPT & -0.0760 & -0.0396 \\
HPT & -0.1429 & -0.0385 \\
MPT & -0.0364 & -0.0379 \\
MPS & $\mathbf{0 . 3 3 1 9}$ & $\mathbf{0 . 3 3 3 3}$ \\
DMA & 0.2413 & 0.1949 \\
VDT & -0.0049 & -0.1158 \\
PPT & -0.1852 & -0.1183 \\
\hline
\end{tabular}

$\mathrm{p}<0.05$ for values in bold; * $\mathrm{p}<0.0029$ (0.05/17; Bonferroni Correction).

$\mathrm{NRS}=$ numeric rating scale; TS $=$ temporal summation; $\mathrm{CPT}=$ cold pain threshold; HPT $=$ heat pain threshold; MPT = mechanical pain threshold; MPS = mechanical pain sensitivity; DMA = dynamic mechanical allodynia; VDT = vibration detection threshold; PPT = pressure pain threshold. 
Table 4 Association between QST measures and psychosocial factors

\begin{tabular}{rcccc} 
& TPC & Knee MPS & Knee DMA & Forearm MPS \\
\hline HAD & & & & \\
Anxiety & 0.117 & 0.1251 & 0.2332 & 0.0498 \\
Depression & 0.178 & 0.1539 & $\mathbf{0 . 2 9 9 4}$ & 0.0275 \\
\hline PCS & & & & \\
\hline Rumination & $\mathbf{0 . 2 6 5}$ & 0.2117 & $\mathbf{0 . 3 1 2 0}$ & 0.1165 \\
Magnification & $\mathbf{0 . 4 0 1 ^ { \star }}$ & $\mathbf{0 . 3 3 7 4}$ & $\mathbf{0 . 3 5 5 0}$ & $\mathbf{0 . 2 8 5 0}$ \\
Helplessness & $\mathbf{0 . 3 3 0}$ & $\mathbf{0 . 3 9 4 6 ^ { \star }}$ & $\mathbf{0 . 3 5 4 8}$ & 0.2259 \\
\hline IPQ-brief & & & & \\
\hline Consequences & $\mathbf{0 . 4 5 2 ^ { \star }}$ & $\mathbf{0 . 3 8 3 3 ^ { \star }}$ & $\mathbf{0 . 3 2 3 7}$ & $\mathbf{0 . 2 8 3 9}$ \\
Timeline & $\mathbf{0 . 3 2 3}$ & $\mathbf{0 . 3 8 2 0 ^ { \star }}$ & $\mathbf{0 . 2 7 7 8}$ & $\mathbf{0 . 2 7 0 0}$ \\
Personal control & -0.125 & 0.0885 & 0.1257 & 0.0255 \\
Treatment control & -0.230 & -0.1237 & 0.0348 & $-\mathbf{0 . 3 0 0 2}$ \\
Identity & $\mathbf{0 . 4 3 3 ^ { \star }}$ & $\mathbf{0 . 2 7 7 7}$ & 0.1980 & 0.2361 \\
Concern & $\mathbf{0 . 4 4 5 ^ { \star }}$ & $\mathbf{0 . 3 6 7 6 ^ { * }}$ & $\mathbf{0 . 2 8 0 1}$ & $\mathbf{0 . 2 9 1 1}$ \\
Coherence & -0.196 & 0.0029 & -0.1074 & 0.0577 \\
Emotion & $\mathbf{0 . 4 0 6}$ & $\mathbf{0 . 3 1 8 5}$ & $\mathbf{0 . 3 3 9 1}$ & 0.1652 \\
\hline Physical Functioning & & & & \\
\hline RAPA & $\mathbf{- 0 . 3 1 1}$ & -0.1339 & -0.0600 & -0.0839 \\
\hline
\end{tabular}

$\mathrm{p}<0.05$ for values in bold; * $\mathrm{p}<0.0036$ (0.05/14; Bonferroni Correction).

TPC = tender point count; MPS = mechanical pain sensitivity; DMA = dynamic mechanical allodynia; $\mathrm{HAD}=$ Hospital Anxiety and Depression Scale; PCS = Pain Catastrophizing Scale; IPQ-brief = IIIness Perception Questionnaire Brief; RAPA = Rapid Assessment of Physical Activity. 
Table 5 Effect of psychosocial factors on the association between pain intensity and QST measures

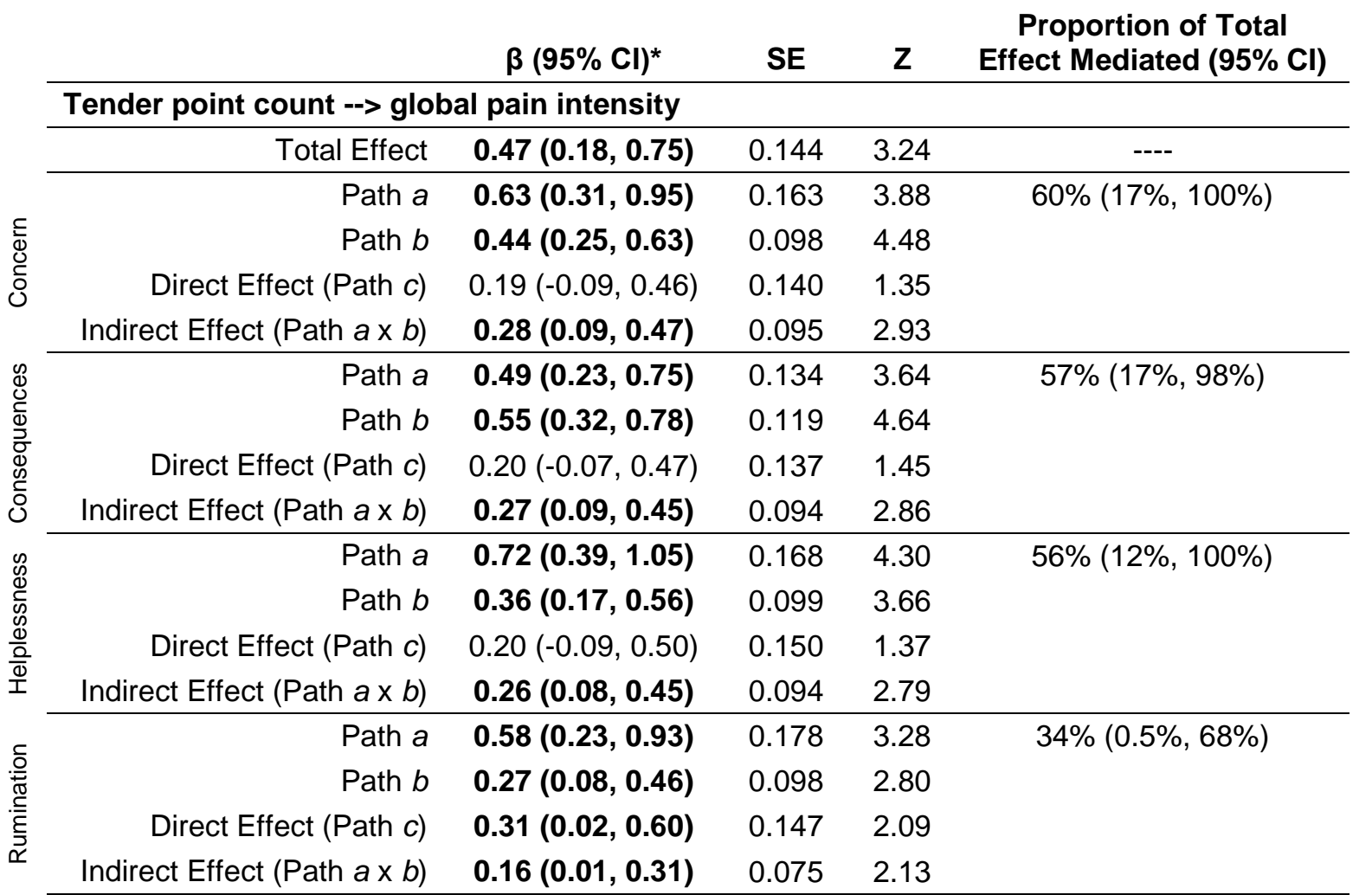

Knee MPS --> global pain intensity

\begin{tabular}{|c|c|c|c|c|}
\hline Total Effect & $0.12(0.05,0.20)$ & 0.038 & 3.26 & ---- \\
\hline Path $a$ & $0.13(0.04,0.22)$ & 0.045 & 2.79 & $45 \%(11 \%, 79 \%)$ \\
\hline Path $b$ & $0.44(0.26,0.62)$ & 0.092 & 4.76 & \\
\hline Direct Effect (Path $c$ ) & $0.07(0.00,0.14)$ & 0.035 & 1.99 & \\
\hline Indirect Effect (Path $a \times b)$ & $0.06(0.01,0.10)$ & 0.023 & 2.41 & \\
\hline Path $a$ & $0.09(0.02,0.17)$ & 0.037 & 2.44 & $40 \%(8 \%, 73 \%)$ \\
\hline Path $b$ & $0.55(0.33,0.77)$ & 0.110 & 4.99 & \\
\hline Direct Effect (Path $c$ ) & $0.07(0.01,0.14)$ & 0.034 & 2.2 & \\
\hline Indirect Effect (Path $a \times b)$ & $0.05(0.01,0.10)$ & 0.023 & 2.19 & \\
\hline Path $a$ & $0.13(0.04,0.23)$ & 0.048 & 2.81 & $40 \%(6 \%, 73 \%)$ \\
\hline Path $b$ & $0.37(0.19,0.54)$ & 0.091 & 4.03 & \\
\hline Direct Effect (Path $c$ ) & $0.08(0.01,0.15)$ & 0.036 & 2.09 & \\
\hline Indirect Effect (Path $a \times b)$ & $0.05(0.01,0.09)$ & 0.021 & 2.30 & \\
\hline
\end{tabular}

Knee MPS --> tested knee pain intensity

\begin{tabular}{|c|c|c|c|c|}
\hline Total Effect & $0.13(0.06,0.20)$ & 0.034 & 3.79 & --- \\
\hline Path $a$ & $0.09(0.02,0.17)$ & 0.037 & 2.44 & $30 \%(4 \%, 57 \%)$ \\
\hline Path $b$ & $0.43(0.23,0.63)$ & 0.103 & 4.19 & \\
\hline Direct Effect (Path $c$ ) & $0.09(0.03,0.15)$ & 0.031 & 2.86 & \\
\hline Indirect Effect (Path $a \times b)$ & $0.04(0.00,0.08)$ & 0.019 & 2.11 & \\
\hline Path $a$ & $0.13(0.04,0.22)$ & 0.045 & 2.79 & $29 \%(3 \%, 56 \%)$ \\
\hline Path $b$ & $0.30(0.13,0.47)$ & 0.088 & 3.41 & \\
\hline Direct Effect (Path $c)$ & $0.09(0.03,0.16)$ & 0.033 & 2.75 & \\
\hline Indirect Effect (Path $a \times b)$ & $0.04(0.00,0.07)$ & 0.018 & 2.16 & \\
\hline
\end{tabular}

$\beta=\beta$-coefficient; $\mathrm{Cl}=$ confidence interval; * $\mathrm{p}<0.05$ if bold. $\mathrm{SE}=$ standard error; $\mathrm{Z}=\mathrm{Z}$-score; MPS = mechanical pain sensitivity. 
Table 6 Mediation analysis for QST measures and self-reported pain intensity including a latent psychosocial

mediating variable

\begin{tabular}{|c|c|c|c|c|}
\hline & $\beta(95 \% \mathrm{Cl})^{*}$ & SE & $\mathbf{Z}$ & $\begin{array}{c}\text { Proportion of Total } \\
\text { Effect Mediated }(95 \% \mathrm{Cl})\end{array}$ \\
\hline \multicolumn{5}{|l|}{ Global Pain Intensity } \\
\hline \multicolumn{5}{|l|}{ Exogenous: Tender Point } \\
\hline Total Effect & $0.47(0.18,0.75)$ & 0.144 & 3.24 & ---- \\
\hline Indirect Effect (path $a \times b$ ) & $0.35(0.13,0.57)$ & 0.112 & 3.15 & $75 \%(22 \%, 100 \%)$ \\
\hline Direct Effect (path $c$ ) & $0.12(-0.18,0.41)$ & 0.149 & 0.77 & \\
\hline \multicolumn{5}{|l|}{ Exogenous: Knee MPS } \\
\hline Total Effect & $0.12(0.05,0.20)$ & 0.038 & 3.26 & ---- \\
\hline Indirect Effect (path $a \times b$ ) & $0.07(0.02,0.12)$ & 0.026 & 2.54 & $49 \%(12 \%, 86 \%)$ \\
\hline Direct Effect (path $c$ ) & $0.06(-0.01,0.13)$ & 0.035 & 1.69 & \\
\hline \multicolumn{5}{|l|}{ Exogenous: Knee DMA } \\
\hline Total Effect & $0.33(0.03,0.63)$ & 0.153 & 2.17 & ---- \\
\hline Indirect Effect (path $a \times b$ ) & $0.21(0.01,0.41)$ & 0.010 & 2.10 & $63 \%(5 \%, 100 \%)$ \\
\hline Direct Effect (path $c$ ) & $0.12(-0.14,0.38)$ & 0.134 & 0.90 & \\
\hline \multicolumn{5}{|l|}{ Knee Pain intensity } \\
\hline \multicolumn{5}{|l|}{ Exogenous: Knee MPS } \\
\hline Total Effect & $0.13(0.06,0.20)$ & 0.034 & 3.79 & ---- \\
\hline Indirect Effect (path $a \times b$ ) & $0.04(0.00,0.07)$ & 0.020 & 2.09 & $30 \%(2 \%, 58 \%)$ \\
\hline Direct Effect (path $c$ ) & $0.08(0.02,0.15)$ & 0.034 & 2.50 & \\
\hline \multicolumn{5}{|l|}{ Exogenous: Knee DMA } \\
\hline Total Effect & $0.43(0.17,0.70)$ & 0.134 & 3.25 & ---- \\
\hline Indirect Effect (path $a \times b$ ) & $0.13(-0.01,0.27)$ & 0.070 & 1.90 & $31 \%(0 \%, 61 \%)$ \\
\hline Direct Effect (path $c$ ) & $0.30(0.05,0.56)$ & 0.129 & 2.34 & \\
\hline
\end{tabular}

$\beta=\beta$-coefficient $\mathrm{Cl}=$ confidence interval; ${ }^{*} \mathrm{p}<0.05$ if bold. $\mathrm{SE}=$ standard error; $\mathrm{Z}=\mathrm{Z}$-score; MPS = mechanical pain sensitivity; $\mathrm{DMA}=$ dynamic mechanical allodynia. 


\section{Appendix A}

\section{Quantitative sensory testing battery}

Tender point count

An 18 point tender point count was performed following the ACR protocol for classifying Fibromyalgia ${ }^{[23]}$. Subjects were asked to rate whether they felt "pressure", "discomfort", or "pain" when pressure was applied to the 9 sites on the right and left sides of the body (18 in total). Pressure was applied by the assessor using their thumb at a rate of $1 \mathrm{~kg}$ per second up to $4 \mathrm{~kg}$ unless the subject indicated discomfort or pain.

\section{Thermal pain thresholds}

Heat and cold pain thresholds were assessed using the TSA 2001-II Thermode (MEDOC, Israel) at the knee and forearm $\left(0\right.$ to $50^{\circ} \mathrm{C}$; MEDOC, Israel). The thermode was set to a baseline temperature of $32^{\circ}$ and increased (heat pain) or decreased (cold pain) in temperature at a rate of $1^{\circ} \mathrm{C}$ per second until the participant indicated pain or until the safety cut-off points at $50^{\circ} \mathrm{C}$ or $0^{\circ} \mathrm{C}$ were reached. Thresholds were determined by taking the average of three readings for each threshold.

\section{Mechanical pain threshold}

Mechanical pain thresholds were assessed using 7 punctate probes $(8-512$ milli-Newton $(\mathrm{mN})$; MRC Systems $\mathrm{GmBH}$, Germany); the probes were applied in ascending order until a participant reported the probe to feel "sharp". Once a "sharp" response was obtained, the probes were applied in descending order until a "blunt" response was achieved. Mechanical pain threshold was determined by taking the geometric mean of the weight of the probes for 5 "sharp" and 5 "blunt" responses.

\section{Mechanical pain sensitivity}

The 7 punctate probes were also used to assess MPS as well as two cotton buds of differing size and a brush to determine DMA as part of the stimulus response function at the knee and forearm. The 10 stimuli 
were applied in a random order and five times each in total with participants asked to provide a rating of pain scored from 0 (no pain) to 100 (worst pain imaginable) for each stimulus. The 35 scores for the punctate probes were averaged to provide a score for MPS with the mean of the 15 responses to the cotton buds and brush forming the score for DMA.

\section{Temporal summation}

Central measures of QST included wind-up ratio at the knee and forearm. A single application of the $256 \mathrm{mN}$ punctate probe and series of 10 applications of the same probe at a rate of one per second was applied to the knee and forearm; participants were asked to rate the single and series of applications using the 0 to 100 NRS described above. Wind-up ratio was calculated from the mean rating of 5 series of applications divided by the mean rating for 5 single applications of the probe.

\section{Vibration detection threshold}

Vibration detection was assessed using a $64 \mathrm{~Hz}$ Rydel Seiffer tuning fork (US Neurologicals, USA); the tuning fork was placed upon the patella or at the elbow while vibrating with participants asked to report whether they felt vibration, and to indicate when the vibration stopped. A scale of 0 to 8 on the tuning fork was used to identify the point of cessation. Thresholds were calculated by taking the mean of three assessments.

\section{Pressure pain threshold}

Pressure pain thresholds were assessed using a hand-held algometer ( 0 to $10 \mathrm{~kg} / \mathrm{cm}^{2}$; Pain Diagnostics and Thermography, USA) with pressure applied at a rate of $1 \mathrm{~kg}$ per second at the knee and forearm until 10 $\mathrm{kg}$ was reached or the participant indicated pain. Thresholds were calculated as the mean of three assessments. 